\title{
Katulongkon: contextualización y antecedentes transculturales del simbolismo de la cabeza entre los Reche-Mapuche
}

\section{Katulongkon: context and cross-cultural background of the symbolism of the head among Reche Mapuche}

\author{
Rodrigo Moulian ${ }^{1}$ y María Pía Poblete ${ }^{2}$
}

\begin{abstract}
Resumen
El artículo contextualiza en términos intraculturales y expone antecedentes transculturales de las variantes del simbolismo de la cabeza en uso entre los reche, etnónimo con el que hasta el siglo XVIII se autodesignan los pobladores originarios del área centro sur del territorio chileno, hoy denominados mapuche. En él exploramos las "constelaciones semióticas" asociadas a este simbolismo. Es decir, leemos series de relaciones de significación que dan sentido a las prácticas de tomar las cabezas de los enemigos muertos en combate, decapitar ritualmente a los prisioneros, usar sus cráneos como trofeos e instrumentos ceremoniales y la conservación o entierro de las testas de parientes y correligionarios para la reproducción del grupo social. La recurrencia y persistencia de estas prácticas entre los grupos amerindios del Cono Sur, así como de los sistemas de representaciones que las contienen, muestran que el simbolismo de la cabeza de los reche-mapuche se inscribe en un patrón cultural panandino y amazónico, en torno al cual se ha desarrollado una cotradición en esta macrorregión.
\end{abstract}

Palabras claves: simbolismo, reche-mapuche, cabeza, cotradición.

\begin{abstract}
This paper contextualizes the variants of the symbolism of the head in use among the Reche, which was the ethnic name for the original inhabitants of southern Chile until the eighteenth century, today named Mapuche. Information is provided in intracultural terms while exposing its transcultural background. We explore the 'semiotic constellations' associated with this symbolism. That is, we read series of meaning relationships that make sense to the practice of taking heads of enemies killed in war, the ritual of beheading the prisoners, the use of their skulls as trophies and ceremonial instruments, and the preservation or burial of the heads of relatives and brethren for the reproduction of the social group. The recurrence and persistence of these practices among Amerindian groups in the Southern Cone, as well as the systems of representations about them, show the symbolism of the head of the Reche Mapuche as part of a Pan-Andean and Amazonian cultural pattern. This means that a cotradition around this cultural pattern has developed in this macro region.
\end{abstract}

Keywords: symbolism, Reche-Mapuche, head, cotradition.

Recibido: 28 septiembre 2016. Aceptado: 24 enero 2017

1 Académico del Instituto de Comunicación Social de la Universidad Austral de Chile, Dirección postal: Austria 2321, Valdivia, CHILE. Email: rmoulian@hotmail.com

2 Académica del Instituto de Estudios Antropológicos de la Universidad Austral de Chile, CHILE. Email: poblete.pia@gmail.com 
El término "mapuche" no se encuentra registrado en las fuentes metalingüísticas del mapudungun de los siglos XVII y XVIII (Valdivia, 1887 [1606]; Febres, 1765; Havestadt, 1883 [1777]). Éstas, en cambio, registran el etnónimo "reche", que significa "gente auténtica”. Boccara (2009) advierte que esta última voz y no la primera es con la que se autoidentifican los miembros de las agrupaciones indígenas del área centro y sur de Chile hasta el siglo XVIII. La referencia a la identidad reche implica, por lo tanto, una alusión a la historia mapuche y sus procesos de transformación, puesto que la mayoría de las prácticas a las que aquí aludimos han dejado de tener vigencia y las concepciones y representaciones que las sostenían se encuentran hoy difuminadas, transformadas o bien presentan un carácter relictual. No obstante, ellas son susceptibles de reconstrucción a través de una arqueología de los símbolos que ofrece una interpretación contextualizada de dichas prácticas. Nuestro trabajo, por lo tanto, se sitúa en primer término en la perspectiva de una antropología diacrónica que emplea fuentes etnohistóricas, lingüísticas, etnoliterarias y etnográficas para reconfigurar estructuras de sentido del pasado. En segundo término, asume una perspectiva etnológica y enfoque comparativo, porque entendemos que la identificación de correlaciones culturales en el área permite atisbar procesos de mayor profundidad histórica.

La voz longko ${ }^{3}$ tiene una doble acepción en la semántica mapudungun, la lengua reche- mapuche. En primer lugar, designa a la "cabeza" parte superior del cuerpo donde se localiza el agne o rostro, que define el $a d$ o $a z$, como se denomina a la fisonomía o semblante de la persona, que constituye una seña de identidad. Etimológicamente, agne (ad-nge) significa el ad que se tiene. Según Valdivia (1887, s.p.) y Febres (1765, p. 424), ad es la cara, frente, la faz o frente de algo. Valdivia explicita que el término se emplea metafóricamente para referir a la forma como se muestran las cosas. Así, la voz admapu designa los modos y costumbres propios de un territorio. Por extensión, el ad refiere a los rasgos

3 Para la escritura de los términos en mapudungun empleamos el alfabeto mapuche unificado propuesto por la Sociedad Lingüística de Chile. No obstante, cuando citamos los términos de esta lengua empleados por otros autores, mantenemos la grafía del original. característicos del individuo (Quilaleo, 2012). Además, la cabeza es contenedor del mollo (cerebro) a través del que se ejerce el pensamiento. Cuando un mapuche califica a otro como "weda longko" (cabeza mala) se refiere habitualmente a su modo de pensar, intencionalidad o carácter. Estos rasgos hacen de la cabeza un significante de la persona.

La segunda acepción del término longko refiere a las autoridades políticas ancestrales, quienes ejercen un rol de representación social y liderazgo en la toma de decisiones. ${ }^{4}$ La crónica de Jerónimo de Bibar (1966, p. 38) evidencia el carácter prehispánico de esta noción. De acuerdo a la fuente etnohistórica, al momento de la llegada de los españoles al valle del Mapocho había en él dos señores: "el uno Tanjalongo [...] manda de la mitad del valle al mar; el otro cacique se dice Michimalongo; éste manda y señorea la mitad del valle hasta la sierra". Febres registra en su diccionario (1765, p. 533) los términos "loncon" y "loncogen" con el significado de "ser, estar a la cabeza; principal, superior". Havestadt (1883, p. 269) consigna la voz "lonco gei” definida como “cabeza, líder, ser principal”. Augusta (1916, p. 116) escribe "lonko" bajo la doble acepción de "cabeza y jefe”. Erize (1960, p. 224), por su parte, señala respecto a esta voz: "Es el vocablo oficial indígena que designa al jefe".

La bifurcación semántica del término muestra que la organización social reche mapuche se representa bajo el modelo del cuerpo biológico, como advierte Boccara (2009). Del mismo modo lo señala la Comisión de Trabajo Autónomo Mapuche (COTAM). De acuerdo a ésta, "el concepto se construye a partir de una analogía con el organismo del che que constituye un todo integrado pero dirigido por el logko / la cabeza. Si la cabeza no funciona bien, el cuerpo sufrirá las consecuencias. Se da una situación similar en los lof, puesto que también es un todo integrado, que debe tener una guía, una buena conducción" (COTAM, 2003, p. 646).

4 Su poder tiene un sustento simbólico, fundado en el prestigio y posición en los grupos de linaje y restringido al espacio social de éstos. La organización social mapuche se caracteriza por un ethos segmental (González 2007) que limita la capacidad de representación social ampliada. 
Los reche mapuche mantienen un sistema de residencia virilocal y de descendencia patrilineal. En el marco de la estructura social tradicional, constituida sobre la base de grupos de parentesco extendidos, el longko es la cabeza künga o linaje predominante o más antiguo del territorio. ${ }^{5} \mathrm{El}$ cargo recae en la persona del grupo familiar más cercano al ancestro fundador, que tenga la capacidad para el desempeño de este rol, expuesto en el conocimiento o kimün, respeto a las normas o norklen que conforman el ad mapu. De acuerdo a la cosmovisión mapuche, quienes asumen el cargo son depositarios del espíritu de sus ancestros. Al respecto testimonia el longko Francisco Ancavil: "Las personas no determinan su vida sino son estos espíritus que regresan los que deciden el destino y don de la persona de acuerdo a su descendencia. Quienes son logko es porque heredaron ese espíritu del logko anterior, de su ascendencia, el que es machi es porque heredó esto de la machi de su ascendencia" (COTAM, 2003, p. 629).

El testimonio del longko Ancavil informa del kupalme püllu (Bacigalupo, 2016) ${ }^{6}$ o parentesco espiritual, el vínculo anímico existente entre los miembros de los grupos de descendencia y sus ancestros. Como nos comentó un longko del área de Imperial, se trata de uno de los componentes de la identidad mapuche que se ha ido perdiendo con el paso del

5 Debido a la disolución de los patrones de organización social tradicional, en el marco de transformación de la sociedad mapuche, el principio de sucesión por descendencia patrilineal ha perdido vigencia en muchas comunidades. Como alternativa se emplean, en la actualidad, otros criterios de selección como la competencia cultural, liderazgos naturales o relaciones políticas. Ello da lugar a continuas disputas y cuestionamientos respecto a la legitimidad de las autoridades étnicas.

6 El término kupalme designa la red de parentesco extendido, que considera las ramas de descendencia de los abuelos paternos y maternos. Éste constituye un sistema de relaciones de afinidad, que compromete el mutuo reconocimiento, la hospitalidad y solidaridad (Course, 2008, 2011). Bacigalupo (2016) emplea el término kupalme püllu para referirse a relaciones de filiación que se establecen entre espíritus encarnados y las personas receptoras de estos espíritus, entre las que no existen necesariamente relaciones de parentesco social. No obstante, el mismo también se aplica a las relaciones de filiación espiritual que se establecen a través de los procesos de encarnación entre los miembros de la red de parentesco. tiempo. Éste resulta conspicuo en el caso de las y los machi, cuyos püllu buscan entre los parientes un cuerpo donde encarnarse, tras su muerte física, y desde allí seguir trabajando. No obstante, este fenómeno no se restringe a los machi, sino que constituye un principio común a quienes ejercen roles institucionalizados o son depositarios de dones. Así nos lo refirió un trutrukakamañ (ejecutante ritual de la trutruka) que conocimos en un ngillatun en la localidad de La Paz, en Loncoche. Pese a sus intentos de rehuir esta responsabilidad ritual, había terminado asumiéndola porque le venía dada por su kupalme püllu y su ejercicio excedía su propia voluntad. Por lo mismo, en la cosmovisión mapuche, la figura del longko se considera depositaria del espíritu animante de los ancestros fundadores, antecesores en el cargo, puesto que como señala el longko Ancavil, son herederos del espíritu de éstos.

Las voces alwe, am y püllu designan en mapudungun a diversas manifestaciones del espíritu. No obstante, el uso de las mismas no es estable, pues supone un sistema de variantes cuyos rasgos semánticos tienden a traslaparse o superponerse. ${ }^{7}$ El término alwe nombra al alma de los muertos, ánima o fantasma (Febres, 1765; Augusta, 1916, p. 6), que Course $(2008$, p. 115) caracteriza como "la fuerza vital impersonal del difunto". Armando Marileo, longko y ngenpin de Puerto Saavedra, caracteriza al am como "el espíritu [...] particular de cada hombre, es el yo invisible o no corporal" (Foerster, 1995, p. 65). No obstante, esta acepción no es generalizada, como ya advirtiera Valdivia en su definición del

7 En términos de la tipología de la cultura de Lotman y la Escuela de Tartu (1979), las culturas orales son culturas gramaticalizadas que proveen principios para la producción de enunciados que generan textos como sistemas de transformación y variantes de estos principios. No se debe esperar en estos casos la estabilidad textual o la cristalización de las representaciones en modelos fijos. Esto es lo que encontramos en el caso de la cultura mapuche, donde coexisten variantes institucionales importantes en espacios geográficamente cercanos, que son transformaciones de su gramática cultural. Esta diversidad se ve acentuada por los procesos de cambio social que ha generado modificaciones e innovaciones en su sistema institucional, así como la pérdida de conocimientos ancestrales. Cualquier estudio sobre la cultura mapuche debe tener en cuenta la variabilidad de los modelos culturales en uso, acentuada por su devenir histórico. 
término (1887, s.p.). Por ejemplo, Febres define al am "como fantasma, bulto o sombra, cosa de la otra vida y el ánima”. Del mismo modo lo hace Augusta (1916, p. 6): "sombra del muerto, a veces el alma separada del cuerpo o el muerto que subsiste de una manera indefinida, más material que espiritualmente". El término püllu se define habitualmente como "alma" (Valdivia, 1887, s.p.; Febres, 1765, p. 608) o "espíritu" (Erize, 1960, p. 341), que de acuerdo a González (2016) residiría en la cabeza. Según Erize, el término designa a los espíritus que han pasado a la otra vida. Un ngenpin del área de Calafquén nos especificó que el püllu era un espíritu intemporal, existente antes del nacimiento de la persona o subsistente a su muerte. ${ }^{8}$ Lo relevante para nuestro caso de estudio, como mostraremos progresivamente en el artículo, es que las narrativas tradicionales, las representaciones cognitivas, el registro histórico de los usos rituales de las cabezas humanas entre los reche y la documentación etnográfica del empleo de cráneos en ceremonias mapuche describen esta parte del cuerpo como un contenedor espiritual.

Por esta razón, en el contexto cultural reche la decapitación o katulongkon es una práctica relevante en términos sociales y cosmovisionarios. Para ellos los cráneos constituyen preciados instrumentos simbólicos con usos militares, políticos y religiosos, a los que se accede a través de la captura de cabezas de los soldados enemigos, la herencia de las mismas a través de las líneas de sucesión o la conservación de los restos de antepasados y correligionarios, que permiten manejar su püllu.

Estas costumbres se inscriben en una tradición cultural que muestra profundidad histórica y amplia difusión en el espacio andino y amazónico y tiene un carácter transcultural (Tello, 1918; Vignati,

8 Course (2008, p. 115) concluye respecto al uso de las voces que designan al espíritu que "el alwe se refiere a la fuerza vital impersonal del difunto; el am a los sedimentos de la personalidad del individuo y el püllu al núcleo interior único del ser". Esta propuesta nos parece sugerente, pero su validez se ve tensionada por la diversidad de usos de los términos. Al respecto advierte el propio autor: "Hay que subrayar, sin embargo, el hecho de que estas tres palabras se empleen de manera tan intercambiable, impulsa una renuencia a sugerir que esto sea algo más que definiciones altamente provisorias".
1930; Proulx, 1971; Tung, 2007; Arnold y Hastorf, 2008; Verano, 2008). Nos encontramos aquí ante un patrón simbólico cotradicional (Figuras 1 y 2). Si bien en el área se advierten importantes variantes y transformaciones formales en el curso del tiempo y su distribución en el espacio, se han identificado en él dos pautas performativas básicas: la captura de cabezas como trofeos de guerra y el culto a las cabezas de los ancestros (Verano, 1995; Nielsen, 2007). Aunque estas conductas no se encuentran en uso en la sociedad mapuche en el presente, persisten numerosos indicios que dan cuenta de la importancia que tuvieron en el pasado.

Pese a la notoriedad y relevancia funcional del simbolismo de la cabeza entre los reche-mapuche, existen pocos trabajos académicos que aborden este tema. Entre las excepciones, destaca la investigación de Villar y Jiménez (2014) que contrasta los usos de la decapitación en los contextos sociales mapuche y colonial en las áreas de la Araucanía y pampeana. Como muestran estos autores, mientras en el primer ámbito el corte de cabezas es fuente de prestigio guerrero que sirve a la reproducción del cuerpo social, en el segundo es un método de castigo dirigido a infundir temor. Por su parte, Acevedo (1995) provee una aproximación exploratoria de este simbolismo en la sociedad "araucana" y muestra su inscripción en el mundo andino, tema que también se encuentra presente en su tesis de grado (1989). Un análisis de las funciones militares y políticas de la decapitación y circulación de cabezas en la sociedad reche se encuentra en Goicovich $(2003,2006)$ y Boccara (2009).

Para profundizar en el estudio del simbolismo de la cabeza entre los reche mapuche, focalizamos nuestra atención en las constelaciones semióticas que se articulan en torno a este motivo. Por "constelaciones semióticas" entendemos aquí el conjunto de relaciones de significación que participan en la representación de la cabeza, estructuras de sentido que se mantienen codificadas en los paradigmas lingüísticos, se despliegan en los discursos en los que se pone en acción el conocimiento y sustentan sus prácticas sociales. Para acceder a esta información, revisamos fuentes etnohistóricas que refieren al uso y simbolismo de las cabezas (Bibar, 1966; Núñez de Pineda, 1863; Rosales, 1877, 1991; González de 


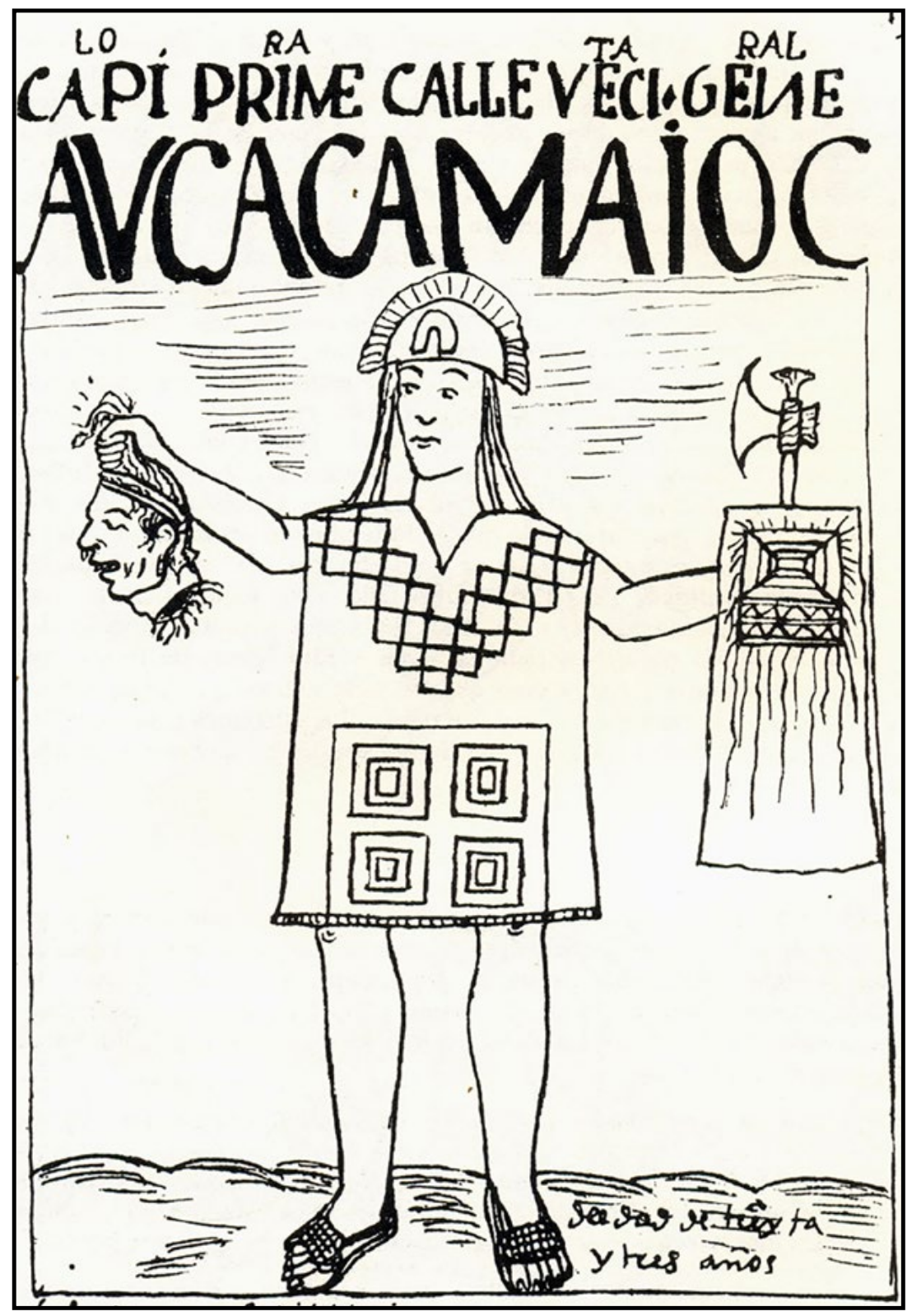

Figura 1. Cabeza decapitada exhibida por un capitán del ejército inca. Dibujo de Guaman Poma de Ayala, en Nueva Coronica y Buen Gobierno. 


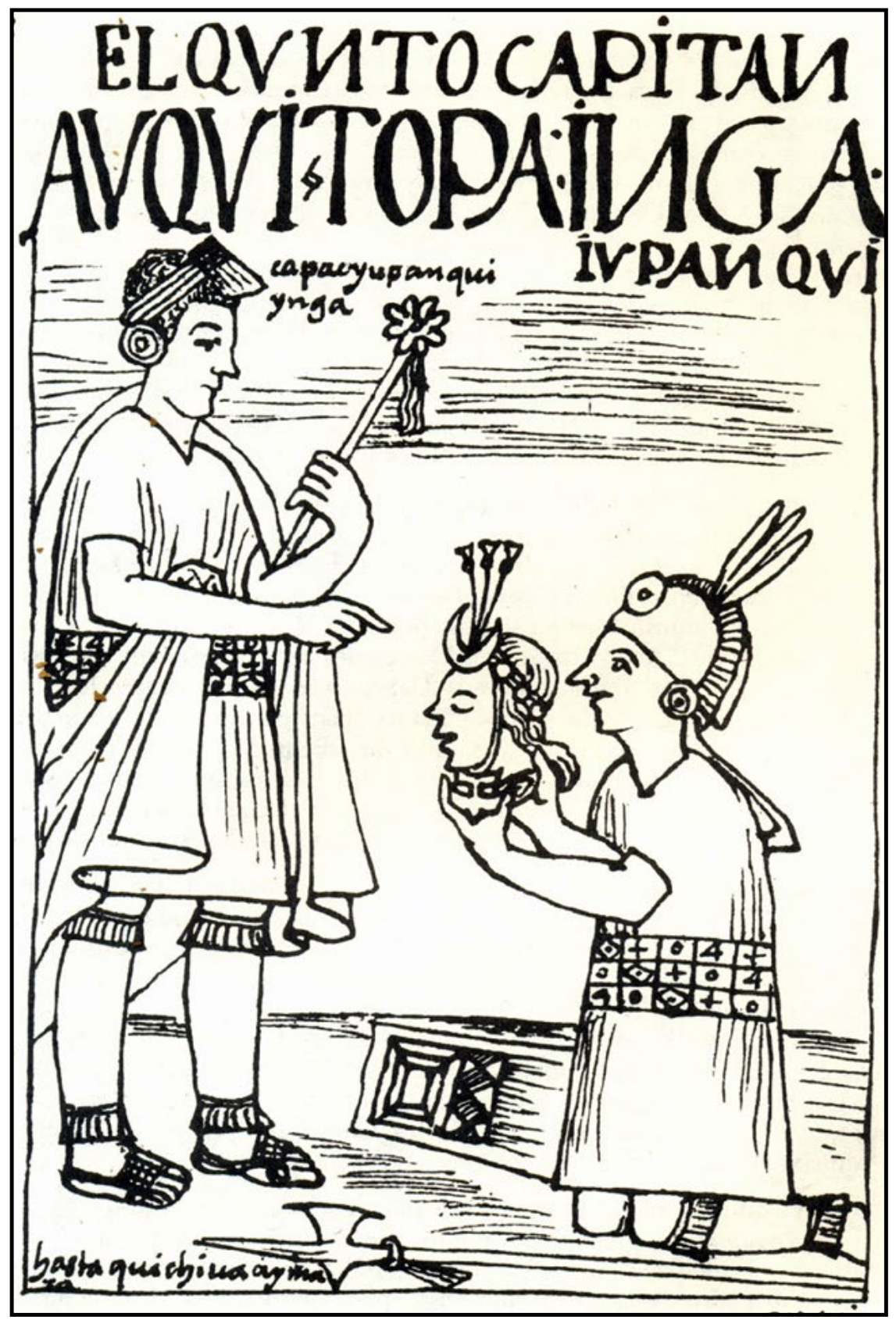

Figura 2. Cabeza trofeo presentada ante el emperador inca.

Dibujo de Guaman Poma de Ayala, en Nueva Coronica y Buen Gobierno. 
Nájera, 1889; Guevara, 1929a y 1929b) y trabajos de metalingüística del mapudungun (Valdivia, 1887; Febres, 1765; Havestadt, 1883; Augusta, 1916; Erize, 1960; Monart, 2005), que registran las voces relacionadas. En un segundo momento, buscamos los correlatos andinos de estas representaciones en la literatura sobre este tema. De modo complementario, hemos realizado un trabajo etnográfico para registrar la vigencia del culto a las cabezas en el área. Con este propósito observamos la "Fiesta de las Natitas” de La Paz, Bolivia, en noviembre de 2015 y el uso de cráneos como protectores de espacios en la caleta de Carquín, distrito de Huacho, y en Cusco, Perú, en mayo de 2016. Lo interesante de estas últimas experiencias es que muestran la persistencia del culto a las cabezas en el contexto andino y entregan información que resulta 'iluminadora' respecto a sus precedentes en el área.

\section{Tripanlongko / Cabeza Voladora}

La figura de la cabeza voladora, recurrente en la mitología mapuche, ilustra la fuerza animante que se le atribuye a este órgano corporal. El término tripanlongko designa en mapudungun a la cabeza que sale del cuerpo. De acuerdo a los mapuche, ello es una manifestación de la capacidad de los/las kalku o brujos, quienes por las noches salen a volar en sus cabezas. Estos viajes, durante los cuales el espíritu abandona sus cuerpos, no se producen de manera etérea, sino encarnada en la testa. Estas cabezas voladoras se impulsan con sus pabellones auriculares o bien asumen las formas de un ave, generalmente un búho denominado choñchoñ o tuetue, por la forma del canto que emite, aunque también se le asocia a otras especies. Su figuración ornitomorfa y anatómica tiende a alternar, combinar y transponerse. Así, Erize (1960, p. 120) sostiene que la voz "choñchoñ" designa la "cabeza con alas en que se convertían los brujos para efectuar sus peregrinaciones nocturnas". La recurrencia de este motivo conduce a Waag (1982) a plantear que el apéndice superior opera en este contexto como contenedor del espíritu.

Según Carrasco, Contreras y García (1998), el choñchoñ es uno de los mitos más antiguos de la cultura mapuche. Su frecuencia y difusión es un indicador de ello, llegando a constituirse en un ícono del imaginario popular chileno (Vicuña, 1915; Plath, 1976; Montecino, Artigas, Phillipi y Obach, 2003). El motivo de la transformación del kalku en "pájaro nocturno-cabeza voladora" se encuentra registrado por autores como Guevara (1908), Salas (1992), Kuramochi y Huisca (1997). Un episodio frecuente en estos relatos es el del amante o pretendiente que llega una noche de improviso a casa de su pretendida. Como no ha anunciado su visita, se encuentra a la mujer tendida de espaldas sobre la cama, pero sin cabeza. La curiosidad o la malicia lo impulsan a poner de lado o boca abajo el cuerpo, posiciones que impedirán que el órgano superior recupere su lugar. Quedan entonces a la espera para ser testigos de esta escena. Al amanecer, la cabeza voladora regresa a la habitación y revolotea desesperadamente sobre el cuerpo, golpeándose contra las paredes. Solo al devolver a éste a su posición original la mujer logra recuperar su condición humana (Guevara, 1908).

Margery (2003) destaca que el motivo de la cabeza animada tiene una amplia distribución en las narrativas amerindias. Un estudio clásico sobre el tema en el área andina es el de Morote (1953), quien plantea el carácter precolombino y panandino del mito. Su figura aparece bajo diversas denominaciones: uma-waqya (cabeza que llama, la que en Ayacucho asocian a un ave nocturna), qepqe (especie de gaviota, considerada una transfiguración de los brujos), uma phawa (cabeza que vuela), uma purej (cabeza que anda), uman tak tak (cabeza que hace tak tak). Los aymara, en tanto, la denominan khate khate (Paredes, 1972). Como muestra el trabajo de Ansión (1987), en el pensamiento quechua esta figura se encuentra asociada principalmente a la brujería. De un repertorio de 27 relatos que recopila en la región de Ayacucho, 20 adscriben a esta concepción. De su vigencia durante el período Colonial Temprano da cuenta González de Holguín quien registra en su diccionario (1989, p. 352) la voz humapurik que define como "las brujas que dizen que las topauan de noche en figura de cabeça humana”.

Sobre el particular, nos dice Ansión (1987, p. 150): "Cuando la bruja se divide en dos, toda su vida se encuentra en su cabeza que vuela. Su cuerpo es 
como un cadáver (aya)". No obstante, la cabeza animada también se encuentra en relatos de condenados por adulterio y cuentos de almas en pena de personas asesinadas. En torno al común denominador que se expresa en estas variantes, Ríos (2008) señala que "en la cosmovisión andina el alma se encuentra focalizada/alojada en la cabeza" (p. 110). Así también lo plantea Millones (2010), quien afirma que la cabeza es el lugar de residencia del nuna, espíritu o sustancia vivificante. García (2010, pp. 258-259) apunta que por esta razón a los enfermos se les cubre la fontanela, para evitar que la energía vital se escape a través de la mollera. En quechua, la mollera o coronilla recibe el nombre de pujyu, que es también el término que designa a las fuentes de agua. Cecilio González, yatiri (médico tradicional) atacameño, afirma que la voz "pujllu" refiere igualmente al alma del difunto, que queda vagando al salir del cuerpo (Uribe, Varela, Cervantes, González y Rodríguez, 2013). Una correlación semántica semejante se encuentra en el mapudungun, donde el término que designa a la fontanela es "lafken" (Ladino, 2014; Hernández y Ramos, 2002). Exactamente la misma voz se emplea para referir a los cuerpos de agua (lagos, mar), que en la cultura mapuche separan el mundo de los vivos y el de los muertos. Ello parece indicar el carácter liminar que se asigna a la mollera.

En el trance de los machi, denominado "koymün", el espíritu chamánico o filew entra a través de ella para asentarse en la cabeza de estos agentes médicoreligiosos, en un proceso que se denomina "longkoluupan" (Bacigalupo, 2007; Erize, 1960). Por esto las machi usan pañuelos y un cintillo de plata denominado trarilongko como elementos protectores de su cabeza a la vez que propiciatorios de su trabajo espiritual. Bacigalupo (2010, p. 89) transcribe el testimonio de una machi que describe este proceso: "El fileu, la machi del cielo, mira estas antiguas plantas-joyas y le gusta. Ve la plata que brilla con el sol. ¡Uy! ¡Qué lindo!, exclama. Le llama la atención. Ve la cabeza de la machi, toda azul con el pañuelo como ofrenda que lo llama y baja de inmediato a la cabeza de la machi”. De acuerdo a los antecedentes que presenta esta autora, durante el trance chamánico el filew monta la cabeza de las machi, cohabita en ellas.

\section{Namculn / Cabeza en la pica}

Según Silverman (1993), el término "cabeza trofeo" fue incorporado en los estudios andinos por Max Uhle a comienzos del siglo pasado, quien interpreta la presencia de las cabezas en el arte peruano como una representación distintiva del simbolismo de guerra. El registro etnohistórico muestra que la decapitación también tuvo para los reche-mapuche un importante sentido simbólico. Por lo mismo, señala Rosales (1877, p. 122), cuando en batalla matan a alguno de sus longko o toki (capitanes) "siempre se ponen en huida, o porque le han muerto la cabeza o por el desmayo que les causó la que vieron enarbolada y por el haliento que causó en los contrarios el buen sucesso". Al respecto, señala el historiador jesuita (1877, p. 121): "el ver la cabeza de alguno de los suyos enarbolada [...] todos cessan de pelear, teniéndolo por mal agüero y por señal que todos han de morir". Ante esta situación "solo tratan de huir y de ponerse en cobro [...] aunque sean ellos mucho y el monton de los que para a cantar victoria con las cabezas poco, no se atreven a acometerlos por más encarnizados que estén" (Ibíd.). Célebre, por ejemplo, es el episodio del ataque de Michimalonco a Santiago, cuando al borde de la derrota Inés de Suarez ordenó degollar a los prisioneros y arrojó sus cabezas sobre la empalizada (Figura 3). Ante este gesto, los asaltantes abandonaron el asedio del fuerte de la ciudad.

En contraste, la captura de la cabeza de un antagonista es celebrada como señal de victoria. "En derribando en la guerra los indios a alguno de los enemigos, se abalanzan luego a él, y mas si es capitán o persona de importancia, y con gran presteza le corta la cabeza y luego lo levantan en una pica, y se atropan los que andan más cerca a cantar victoria sobre ella” (Rosales, 1877, p. 121). Según anota Febres (1765, p. 572), el término “ñamculn" designa la práctica de "enclavar la cabeza de la gente en un palo, como hacen quando cantan victoria de sus enemigos". Este término corresponde a una metáfora que expresa la felicidad del aguilucho cuando atrapa a sus presas (Boccara, 2009) y las exhibe en sus garras. Al respecto, testimonia Rosales (1877, p. 122): "La cabeza con la que cantan victoria la llevan a su tierra y la cuelgan como estandarte o vandera 


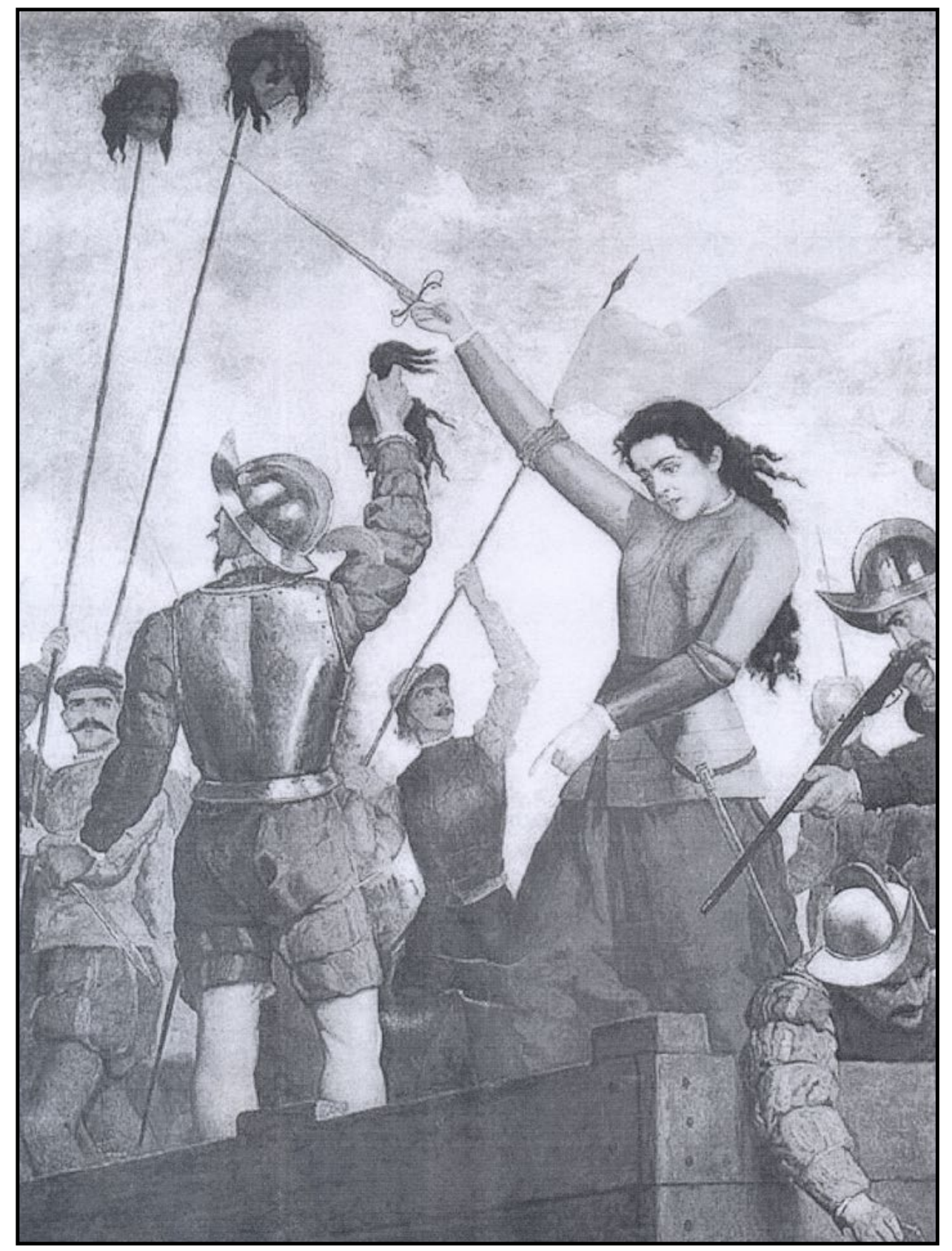

Figura 3. Inés de Suárez decapitando a caciques prisioneros. La exhibición de las cabezas ocasionó la huida de los combatientes reche durante el asedio a Santiago en 1541. Óleo de José Ortega, Colección Museo Nacional. 
que le han quitado al enemigo y la ponen en la parte pública después de averla emviado a las provincias en otras para hazer ostentación de su victoria, y que sepan que tienen a aquel capitán menos por enemigo." Éste fue, por ejemplo, el destino de Pedro de Valdivia, primer capitán general del reino de Chile, de quien nos dice Bibar (1966, p. 171): "Llevaron la cabeza a Tucapel y la pusieron en la puerta del señor principal en un palo y a otras dos cabezas con ellas, y teníanlas por grandeza, porque aquellos tres españoles habían sido los más valientes, y contaban cosas del gobernador y de los dos españoles que habían hecho aquel día”.

En el contexto de la cultura bélica reche, la captura de cabezas es un símbolo de poderío guerrero, que permite a sus poseedores la acumulación de prestigio militar y poder político. Por lo mismo, las cabezas ganadas se exhiben en el espacio público y se ponen en circulación entre las parcialidades vecinas, para anunciar las victorias e incitar a otras agrupaciones a sumarse a la guerra. Así sucede con el gobernador Martín Óñez de Loyola y su hueste, derrotada en el combate de Curalaba el 23 de diciembre de 1598. Sobre este episodio Rosales relata (1878, p. 302): "Y entonces fue tanto el gusto, y la fiesta que hizieron, que yendo al toldo del gobernador, (junto a donde avía muerto) le cortaron la cabeza, y con ella puesta en una pica, cantaron victoria, y cortando otras de los capitales las llebaron por trofeo, y para hazer fiesta con ellas, y repartirlas por las demás Prouincias para que se alzassen las que estaban en paz". En este caso, la muerte y decapitación de Óñez de Loyola tiene un efecto multiplicador, pues conduce a un alzamiento generalizado y la destrucción de las siete ciudades del sur de Chile.

La cabeza del gobernador queda en manos del toki Pelantaro, principal líder militar del alzamiento (Rosales, 1878). Del mismo modo había sucedido previamente con el cráneo de Pedro de Valdivia, que permanece en poder de Caupolicán (Rosales, 1877). El movimiento de estos órganos hacia quienes ejercen como líderes de la organización militar constituye un modo de fortalecer el cuerpo social, como advierten Villar y Jiménez (2014). Las cabezas de los capitanes y soldados son, asimismo, enviadas a otras parcialidades como un mecanismo de articulación y movilización social. La recepción de cabezas trofeo impone a los destinatarios la obligación de retribuir el gesto para no quedar en una situación de inferioridad simbólica y subordinación. Como apunta Boccara (2009, p. 185): "No devolver la cabeza del enemigo de los cautivos recibidos, implica mantenerse en una posición de receptor y, por lo tanto, de dominado, de inferior". Se cumple aquí el principio del "travloncon", término que designa la práctica de devolver una cabeza por otra, como se denomina también la costumbre de pagar una muerte con otra muerte. Según Guevara (1929b, p. 200) la expresión viene de "trav", que significa correspondencia, retorno y "lonco", cabeza. La voz connota un principio de reciprocidad que articula la vida social mapuche. Por lo mismo, las cabezas que circulan tienen un poder movilizante, pues obliga al receptor al gesto equivalente. En contraste, advierte Valdivia (1852, p. 284), quienes daban las paces a los españoles arriesgaban que las demás parcialidades tomasen las suyas.

Esta función política del simbolismo de las cabezas ha sido ampliamente discutida por Arnold y Hastorf (2008) en el mundo andino, en general, y aymara, en particular, exponiendo patrones que resultan concordantes a los reche-mapuche. De acuerdo a estos autores, las prácticas asociadas a este motivo movilizan concepciones de la corporalidad y las fuerzas anímicas en los procesos de acumulación de poder de distintos grupos sociales. En la concepción aymara, el alma mora en la cabeza y posee una fuerza generativa (Arnold y Espejo, 2007). La caza y uso simbólico de las cabezas es una forma de apropiación o neutralización de esta fuerza para el propio interés. Un caso etnográficamente conspicuo es el de los shuar (Harner, 1978; Flornoy, 1953; Karsten, 2000), más conocidos como jíbaros, famosos cazadores y reductores de cabezas de la Amazonía ecuatoriana. Entre ellos, la función específica de esta práctica es impedir que el mésak o espíritu vengador del difunto actúe contra los vencedores (Harner, 1978). Al capturar y reducir la cabeza, hacen que el mésak quede atrapado en ésta, motivo por el cual suturan su boca para evitar que escape. Por su parte, las mujeres acompañan el proceso entonando cánticos que buscan aplacar al espíritu e incorporarlo a su grupo de afines. De este modo ellas pueden aprovechar su energía y aumentar la productividad de sus cultivos, crianza de ani- 
males domésticos o propiciar su propia fertilidad. En palabras de Descola (2002, p. 166), el ritual de la cabeza trofeo reducida o tsansa también apunta "a privar al muerto de su identidad originaria para transferirla al grupo social del asesino donde se convertirá en un principio de producción de un niño que está por nacer".?

No obstante, como advierte Mader (1999, p. 199), la ritualidad que acompaña a estas operaciones "forma parte ideológica y espiritual de la guerra", a través de las que se pone de manifiesto el poder militar, político y la capacidad económica de los grupos de alianza. Karsten (2000, p. 225) señala que entre ellos "la regla es que un guerrero que ha capturado una cabeza, tsantsa, debe celebrar una fiesta. La fiesta de la cabeza abre para el jíbaro el camino hacia el honor, la fama, la riqueza material, hacia nuevas victorias sobre el enemigo y hacia una vida larga”. De modo similar apunta Mader (199, p. 201): "La realización de la ceremonia de la tsantsa no solo aumenta el prestigio del guerrero que cortó la cabeza al enemigo, el de su mujer y sus familiares cercanos, sino que contribuye al prestigio de todo el grupo de alianza". ${ }^{10}$

9 Los fundamentos etnográficos de esta afirmación se encuentran desarrollados por Descola en Las Lanzas del Crepúsculo (2005). En esta obra, muestra que la cabeza adopta posiciones de afinidad con los participantes en los cantos y acciones performativas del ritual de la tsantsa y representa metafóricamente el vientre de la esposa del guerrero como si estuviera embarazada. En palabras del autor: "El ritual de tsantsa convierte a un enemigo no pariente en un hijo consanguíneo".

10 La producción de cabezas trofeo entre los shuar tiene una función simbólica enunciada explícitamente: impedir la venganza espiritual, lo que en el caso reche mapuche es más difuso, en tanto no se encuentra formalizada. No obstante, Goicovich (2003) plantea que las prácticas reche de consumo y manipulación corporal de los vencidos apuntaban a impedir que sus espíritus continuaran luchando contra ellos en la otra vida. Aun así, nuestra alusión al caso shuar se debe principalmente a la función sociopolítica de la caza de cabezas donde consideramos que existe una clara analogía con el caso reche-mapuche. Esta relación de la caza de cabezas shuar con el prestigio y el poder se encuentra identificada por Kartsen (2000 [1935]) y Hartner (1978) quienes se encuentran entre los pocos etnógrafos que han sido testigos directos de esta actividad.
El funcionamiento de la cabeza trofeo como nudo simbólico, que presenta múltiples funciones y conecta con diversas dimensiones de la vida social, también se advierte entre los munduruku (Santos, Salles, Mendonça de Souza y Nascimento, 2007; Savio, 2007), que habitan en los estados brasileños de Pará, Amazonas y Matogrosso, cuya lengua pertenece a la familia tupi guaraní. Los munduruku son un pueblo guerrero, que acostumbraba cazar a sus enemigos y capturar a sus mujeres y niños. A diferencia de los shuar, no son reductores de cabezas, sino embalsamadores. Retiran de éstas las partes blandas, las sumergen en aceites naturales que favorecen la conservación de la piel y las dejan secar. En el cabello trenzan cordones de algodón con plumas de tucán rojo y negro. A través de la boca pasaban un cordón para que los guerreros pudieran llevar las cabezas o amarrarlas en sus cinturas en las fiestas, expediciones de caza o guerra. Durante la noche, eran dispuestas en un poste frente a la casa de los guerreros.

Para los munduruku estas cabezas trofeo son objetos de prestigio que aumentan el estatus de su poseedor, en tanto se consideran elementos propiciadores de la caza y símbolos de reproducción del grupo social. Sus poseedores reciben el título de Dajeboichi que significa "la madre de pecarî" y hace alusión a la adopción de los niños que son capturados en las incursiones guerreras (Menget, 1996). En los rituales que siguen a la obtención de las cabezas, éstas van a recibir las marcas corporales (corte de cabello y tatuaje facial) propias de los munduruku, lo que se puede considerar como signos de incorporación social. En tanto, cuando un guerrero munduruku muere en las expediciones bélicas, sus compañeros retornarán con su cabeza para enterrarla en el suelo de su casa, un patrón que como veremos más adelante se inscribe en las prácticas de ancestralización.

Las prácticas de las cabezas trofeo en los casos shuar y munduruku se inscriben en una lógica denominada por Fausto (2001) "predación familiarizante", que exponen un consumo productivo que simbólicamente se apropia del espíritu de los muertos. Ellas se realizan en el marco de empresas bélicas que impulsan el desarrollo de relaciones sociales generalizadas y se acompañan de reseñas que refuerzan los lazos internos y operan como signos de prestigio y poder. 


\section{Katuchen / Trozar a la gente}

"Catuloncon" (Valdivia, 1887; Febres, 1765) o katulongkon, como se designa a la decapitación entre los reche, no se restringe a la toma de la cabeza de los contrincantes muertos en batalla; se practica igualmente en forma ritual con los prisioneros capturados en combate y conservados vivos para este propósito. El proceso sacrificial supone la apropiación del cuerpo de las víctimas, el que es desmembrado y descarnado en una faena denominada "katuchen", término que también es empleado para referir a la práctica de cortar cabezas (Monart, 2005, p. 189), pero que literalmente significa "trozar a la gente". Rosales (1877, p. 128) informa que solo el año 1655 fueron sacrificados más de 150 españoles cautivos en el marco de las ceremonias reche, los que eran ejecutados de a dos o tres para "hacer más solemne la fiesta". Aquí el descabezamiento se realiza en el marco del consumo material y simbólico del cuerpo de los enemigos, destinado a captar y controlar su energía vital (Boccara, 2009; Villar y Jiménez, 2014). El corazón, la sangre y la carne sirven de alimento ritual, los cráneos devienen en trofeos, símbolos evocadores e instrumentos propiciatorios.

El proceso de ejecución se encuentra descrito detalladamente por testigos del mismo como Núñez de Pineda (1863), Rosales (1877) y González de Nájera (1889). A las víctimas se las designaba huequeche (wekeche), término que las homologa con las llamas (bueque / weke), piezas del ganado camélido andino que empleaban de modo sustitutivo en sus sacrificios (Rosales, 1877). Quienes iban a morir eran conducidos con sus manos atadas hasta una cancha de ceremonias denominada "lepün" y se las inmolaba, generalmente de un golpe de maza en la cabeza (Figuras 4 y 5). Según Guevara (1929a, p. 347), a la macana con que se desarrollaba este procedimiento daban el nombre "lonco quillquill", es decir, cabeza de chuncho (Glacidium namun), ave nocturna que asocian a la muerte.

Apenas derribada la víctima, le abrían el pecho para sacarle el corazón palpitante cuya sangre era bebida y su carne comida por los principales integrantes del grupo. Las piernas y brazos eran cortados y descarnados para fabricar con sus huesos flautas que empleaban en sus ceremonias. La piel del tronco la destinaban para elaborar tambores con los que animaban los bailes. Cuando la inmolación se realizaba en encuentros entre diferentes parcialidades, los miembros de una ejecutaban al prisionero, los de otra le cortaban la cabeza, los de una tercera le sacaban el corazón, de modo que los participantes quedaban unidos por el sacrificio. González de Nájera (1889) señala que algunos prisioneros eran desollados vivos, su carne cortada paulatinamente en tajos y consumida con el sujeto sacrificado aún en vida; sus huesos eran machacados, luego mezclados y bebidos con chicha.

Adviértase la notable similitud respecto a las costumbres del incario informadas por Guaman Poma de Ayala (1980, p. 124): "Beberemos en el cráneo del traidor; nos colgaremos sus dientes; en sus huesos tocaremos flauta; con su piel haremos un tambor y cantaremos", rezaba -de acuerdo a este autor- la ley inca contra los enemigos del Estado. El proceso de desmembramiento, consumo material y uso simbólico del cuerpo era similar en estos dos pueblos. Al respecto detalla el cronista de Indias: “... de la cabeza hacían mate de beber chicha, de los dientes y muelas gargantillas, de los huesos flautas, de los pellejos tambor".

Como veremos, en este contexto ritual la cabeza tiene un valor privilegiado. El uso ceremonial que los reche-mapuche dan a esta parte del cuerpo muestra que le atribuyen una relación vinculante con los espíritus de sus enemigos y atributos de un poder visionario o premonitor. Así informa Rosales (1877, p. 125): "El que cortó la cabeza la echa a rodar por el suelo hazia la tierra de el enemigo, y abre una calle la gente, por donde la lleba rodando, y toman tabaco en humo y por la misma calle le van echando a vocanadas, retando al enemigo y diciendo que con los que alla están han de hazer lo mismo. Y si la cabeza se queda el rostro hazia el enemigo, lo tienen por buena señal y dizen que han de alcanzar victoria; pero si se queda vuelta hazia ellos lo tienen por mal agüero y temen que les ha de ir mal en primera ocasión". Aunque el donante ha perdido la vida, su cabeza mantiene una capacidad expresiva. 


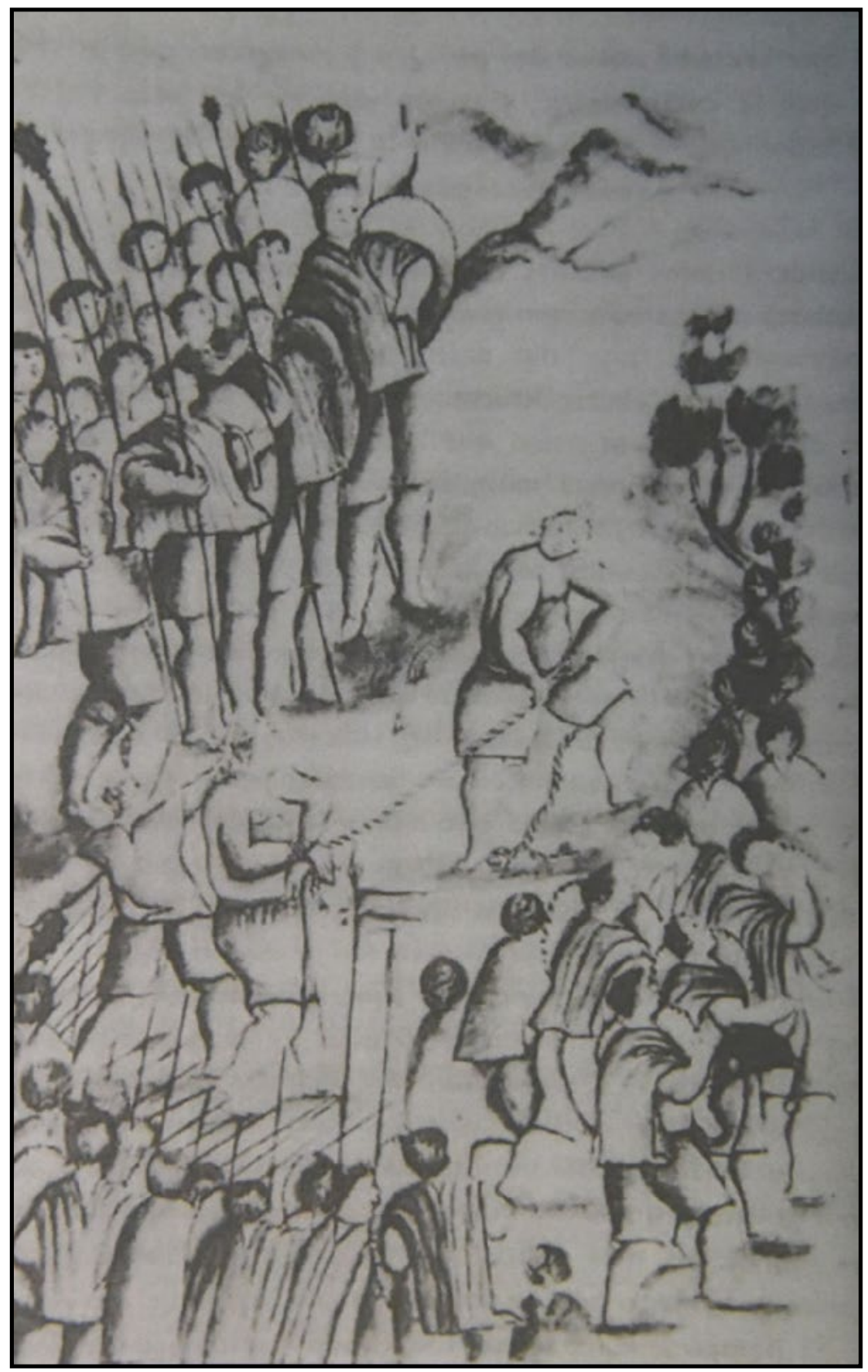

Figura 4. Cautivo español conducido al espacio sacrificial mapuche. Dibujo de Francisco Núñez de Pineda y Bascuñán en el Cautiverio Feliz. 


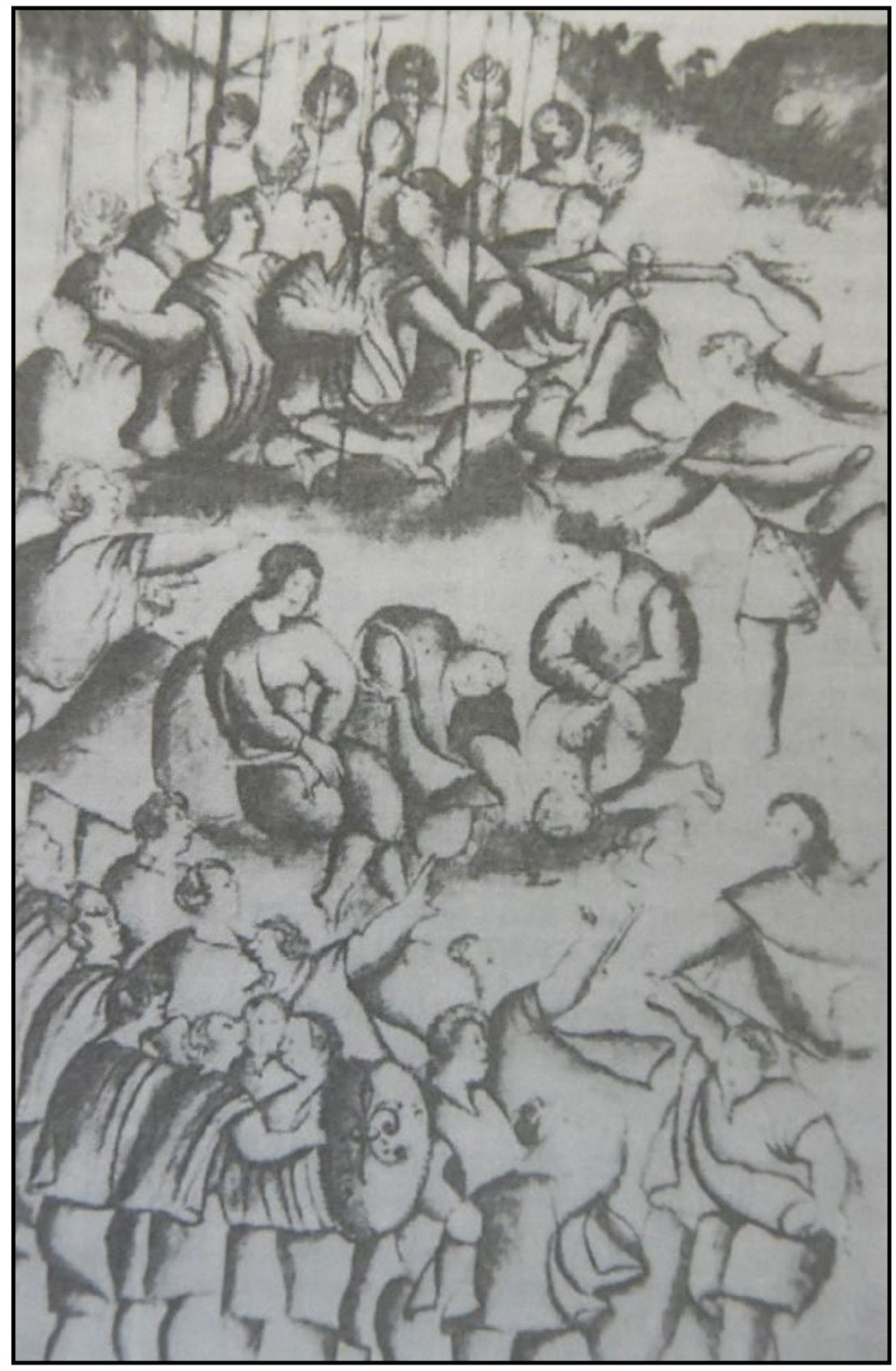

Figura 5. Muerte de un prisionero español por golpe de macana. Dibujo de Francisco Núñez de Pineda y Bascuñán en el Cautiverio Feliz. 


\section{Ralilongko / El cráneo como vaso}

Un cuidadoso proceso transforma la testa en presea de guerra y objeto simbólico. En primer término, ésta es desollada para hacer con su piel una máscara denominada "mañawe" que usaban en ocasiones rituales, estimando en especial las que tenían barbas y bigotes. El cráneo era cocido, el cerebro y los restos de carne retirados para hacer del casco un recipiente denominado "ralilongko" (Rosales, 1877), término que literalmente significa "plato cabeza", pero que cumple la función de vaso, algunos de los cuales eran decorados con pinturas (González de Nájera, 1889). En ocasiones solemnes, los principales integrantes de las agrupaciones empleaban estos recipientes óseos para beber en forma comunitaria. Así lo consigna Rosales (1877, p. 123): "Guardan el casco despues de averle pelado y descarnado en agua caliente $[. .$.$] y en las borracheras de mucho concur-$ so le sacan para beber en él por grandeza, de suerte que solamente los caciques y las personas grabes beben, por honra que se les haze, en la cabeza, que llaman Rali-lonco, que quiere dezir vaso de cabeza, en el qual no bebe jamas la gente vulgar".

Las cabezas son empleadas en momentos de intensificación ritual como las rogativas o en asambleas militares: "en las ocassiones de guerra o de alzamientos la saca como estandarte Real que quitaron al enemigo, y para animar a todos sus soldados y provocarlos a la guerra con la esperanza de coger otra cabeza semexante y con el exemplo de sus antepasados que ganaron aquella" (Rosales, 1877, p. 123). En estas ceremonias acostumbraban beber en ellas, brindaban en nombre de los ancestros y recordaban sus hazañas y glorias. La cabeza convertida en vaso opera como dispositivo de memoria, que mantiene codificada la historia, y aparece acompañada del efecto animante de las bebidas fermentadas, denominadas pülko, "agua del espíritu".

El término quechua "uma putu", que designa a la "cabeza taza", es un calco semántico de ralilongko. En lingüística se emplea este concepto para referir a una voz que reproduce de manera idéntica, pero en otra lengua, la estructura semántica de un lexema. Ello revela la existencia de correlatos culturales, en este caso, de la práctica de beber en las cabezas.
Los incas acostumbraban repujar los cráneos con oro y plata para producir vasos rituales. Célebre, por ejemplo, es el caso del Inca Atahualpa que bebe en el cráneo de su hermano Huáscar, al que derrota en una guerra de sucesión. La misma práctica se encuentra documentada entre aymaras (Arnold y Hastorf, 2008; Abercrombie, 2006) y guaycurúes, chiriguanos, abipones, tobas (Vignati, 1930), lo que expone un patrón transcultural. Saignés y SalazarSoler (1993), por su parte, han hecho evidente la relación existente entre el consumo comunitario de bebidas y el ejercicio de la memoria, que se repite en el caso mapuche.

La posición y uso privilegiado que asumen los cráneos en los ceremoniales reche muestran que ellos constituyen símbolos primarios, altamente valorados y significativos, como se advierte en la siguiente cita de González de Nájera (1889, p. 56): “En lo alto a la redonda de sus ramas, ponen las cabezas de los espańoles que han muerto, cada una en su rama de manera que se ven los rostros desde fuera, las cuales tienen adornadas de flores y guirnaldas, i algunas ponen sus mismo zarcillos algunas indias [...]". En ella, el cronista describe la colocación de cabezas humanas en los rewe, término que designa a los instrumentos y espacios de mediación entre los mapuche, sus deidades y espíritus de los antepasados, en torno a los que se reúnen las congregaciones rituales. El rewe constituye un espacio sacralizado.

Al respecto, continúa el relato de este soldado de la conquista: "De las ramas donde están las cabezas bajan unas cuerdas de lana de diferentes colores, que cada una viene a tener en la mano un cacique [...] y al mismo tiempo van tirando los caciques de las cuerdas desde sus bancos dó están de pies de manera que al compás del general movimiento y modo común del baile hacen también menear o bailar las ramas con las cabezas que está en ellas" (Ibíd.). La danza es una de las principales acciones rituales mapuche, que se realiza -habitualmente- en torno al rewe. La que aquí se describe recibe el nombre de purulongkon cuya traducción literal es "el baile de la cabeza". Ello muestra cómo se hace participar a las testas de la acción ritual, marcando la relación de dominación que los depositarios ejercen sobre sus trofeos óseos. 
Los cráneos son guardados y pasan de generación en generación "como pressa de grande estima y que passa de padres a hixos como vínculo de mayorazgo" (Rosales, 1877, p. 123). Cuando matan a un capitán o persona de importancia, su cráneo lo conservan los capitanes, denominados “toki”. La cabeza de Valdivia quedó en manos de Caupolicán, la de Óñez de Loyola en poder de Pelantaro. Sus descendientes las atesoran como bienes de gran valor y se niegan a devolverlas por más pagas y haciendas que les ofrezcan. Así lo testimonia Rosales (1877, p. 123): "tiene hasta oy en Tucapel un cacique la cabeza de el gobernador Loyola y la saca en fiestas recias para brindar en ella a los caciques. Y aunque le daba por ella el capitan Juan Catalan mucha hazienda, assi por enterrarla como por quitarles esa vanagloria de blasonar que mataron a ese gobernador, no se la quiso dar, porque la estima como vínculo de mayorazgo. Y lo mismo le sucedió despues al mismo capitan Juan Catalán, que tubo gran fama en su tiempo, que aviéndole muerto los indios en el rio Bueno, passó despues su cabeza por toda la tierra y la tienen guardada los indios de la costa como una gran pressa”.

\section{Ancestralización}

He practicado el ñamkuln con mis kona, para enseńarles cómo sostener la cabeza traspasada con la lanza. Con dignidad sabían llevarlas, con altivez. Y en el purulon, el baile de los enemigos matados, hicimos bailar sus cabezas; balanceándose en las ramas del canelo sagrado estaban, bamboleándose colgaban, mientras bebíamos para que se repitiera el hermoso kauiñ [fiesta]. ¡Más fuertes, más fuertes mis acordes! Gritar deben, como mi canción, pues saben historias cruentas, leyendas de roja sangre de enemigos (KoesslerIlg, 2006, p. 54).

La importancia que los sujetos mapuche daban a la captura de cabezas como enseńa de prestigio queda reflejada en la cita precedente, que forma parte de la "Canción del 'Adiós a la vida' del condenado Apo ülmen, lonko Kurupillañ”, narrada por el centenario Kinchahuala (Koessler-Ilgr, 2006, pp. 42-62). Ante la inminencia de su muerte, al pie del patíbulo, un cacique pasa revista a los eventos más rele- vantes de su vida. La captura y uso ritual de cabezas aparece como un hito biográfico narrado con orgullo, descrito como un momento glorioso de ribetes épicos que prestigia al hablante y lo hace digno de transformarse en ancestro. La reproducción del relato por Kinchahuala muestra la incorporación de sus actos rituales en la trama de la memoria en la que el narrador y protagonista del relato continúa viviendo.

No obstante, y aunque menos registrado, el uso de las cabezas no se limita a la decapitación de los enemigos, sino que incluye la conservación de los cráneos de parientes y correligionarios. Así informa Rosales (1991, pp. 69-70) que en Toltén "[...] un indio viejo llamado Paiyalleco conservaba la cabeza de un indio, que hacía sesenta años, que había muerto, el cual había sido entre ellos muy estimado por ligero, y gran jugador del juego de la chueca”. Este indio Paiyalleco "se valía de artes diabólicas $\mathrm{y}$ de invocaciones para ganar y tener ventura en el juego. Y cuando habían de armar algún juego de chueca, que es entre ellos muy célebre y de muchas apuestas, e intereses para el que gana, la noche antes hacían grandes prevenciones, ceremonias diabólicas y invocaciones para ganar al día siguiente a los contrarios". Según el relato del cronista de la Conquista Espiritual del Reino de Chile, previo a un encuentro de palín, los de Toltén "estuvieron toda una noche haciendo invocaciones al demonio con la cabeza del indio Paillayeco, pidiéndole ventura para ganar incensándole con tabaco, lavando la bola y las chuecas con que juegan, cantando alrededor, echándole tierra de difuntos".

Domeyko (2010) testimonia, igualmente, el uso de cráneos de afamados jugadores para propiciar la suerte de las partes en el juego. En el episodio que relata, el motivo de la competencia de chueca era decidir si permitirían la reinstalación de la misión en Tucapel. Según el autor: "cada uno de los bandos trajo el cráneo de uno de los jugadores más célebres y los colocó en su raya para que el espíritu del muerto que en vida conoció la gloria de muchos triunfos se alegrara del buen ánimo de los araucanos y dirigiera los destinos del juego" (p. 147). Tras tres días de lance, la suerte favoreció a los partidarios de la misión. 
La persistencia de esta práctica hasta el presente ha sido documentada etnográficamente en la comunidad de Quetrahue, Lumaco, por Oyarce y González (1986) y López (2011). En ella se conserva el cráneo de un afamado jugador llamado Kudefe, también denominado metafóricamente Kallfülikan (pedernal azul). El nombre designa a la calavera, pero también al jugador difunto, que se encuentran en relación de sustitución y equivalencia, de modo que el primero remite al segundo y a la inversa. El cráneo se emplea en una ceremonia exclusivamente masculina denominada ngechall kona, que significa "animar a los mocetones", dirigida a los miembros del equipo de palín. Ella se realiza generalmente de noche tras una ceremonia comunitaria o konkünungillatun. La cabeza se pone en un rewe conformado por una vara de colihue y canelo. Los jugadores se sitúan en torno a él, donde bailan y entonan un extenso ül (canto ceremonial) dirigido a Kallfülikan: “...jugará, jugará/ jugará el día de mañana Kallfülikan / (...) aquí, aquí, aquí / en este paliwe sagrado / (...) azul, azul, azul, azul/ se pondrá la calavera/ donde jugará el día de mañana/ Kallfülikan..." (Oyarce y González, 1986, pp. 254-266).

El antropólogo Aldo Vidal, ${ }^{11}$ quien fue testigo de una de estas ceremonias el año 1980, afirma que los palife bebieron muday en el cráneo. De acuerdo a Oyarce y González, el protocolo ritual tiene como propósito el traspaso de la energía y habilidad de Kallfülican, considerado el mejor exponente de la chueca que ha tenido la comunidad de Quetrahue, a los demás jugadores. Según hemos podido averiguar, la cabeza se emplea, igualmente, en los procesos de iniciación simbólica de éstos.

Por su parte, la profesora intercultural Claudia Inglés $^{12}$ nos refirió que entre los mapuche de la costa de Valdivia aún persiste el recuerdo de que en el pasado los antiguos enterraban bajo las rucas los cráneos de los fundadores de linaje como una manera de mantener la unidad y asegurar el cuidado de la familia. Los antecedentes previamente referidos informan de un patrón de ancestralización, como se denomina a los elementos que participan del culto a los antepasados, que en la religión mapuche tie-

11 Aldo Vidal, com. pers., febrero 2016.

12 Claudia Inglés, com. pers., marzo 2015. nen un lugar relevante (Guevara, 1908; Latcham, 1924; Grebe, Pacheco y Segura, 1972; Faron, 1997; Dillehay, 1990; Foerster, 1995; Moulian y Espinoza, 2014; Rojas, 2016a, 2016b). De acuerdo a las concepciones mapuche, los espíritus de los ancestros se mantienen en contacto con los miembros de su grupo de filiación, se comunican con ellos a través de los sueños y velan por su bienestar. En correspondencia, sus parientes vivos les brindan cuidados rituales a través de oraciones y ofrendas. De no hacerlo de manera apropiada, estos espíritus los podrían castigar. ${ }^{13}$

Como resultado de los cambios socioestructurales, producidos en el marco de las relaciones de contacto, la centralidad de este culto se ha ido perdiendo, especialmente en congregaciones donde los/las machi asumen relaciones sacerdotales (Bacigalupo, 1995). No obstante, éste se mantiene vigente en comunidades donde las transformaciones han sido menos intensas o más tardías. Por ejemplo, en el área de Loncoche, Lanco, Panguipulli y Calafquén, el culto se expresa en los ngillatun o rogativas comunitarias a través de diversos actos rituales. Entre ellos, la visita preliminar al cementerio para propiciar la participación de los ancestros en las ceremonias; la invocación en las oraciones centrales a los ancestros fundadores de los linajes dominantes y la disposición de un momento especialmente dedicado

13 Por lo mismo discrepamos de Course (2008) para quien los espíritus ancestrales carecen de agencia. De acuerdo a este autor, en la cultura mapuche "no hay elaboración con respecto al destino del alma luego que es enviada a su rumbo y consecuentemente no hay conexión entre ancestro y vitalidad" (Course, 2008, pp. 215-216). Esta ausencia de un modelo escatológico cristalizado impediría que los espíritus constituyan "una fuente genérica de fertilidad y benevolencia” (p. 117). Del mismo modo, diferimos de Di Giminiani (2012, p.130) según quien "Al contrario de lo que ocurre en las tierras altas, la connotación que tienen los antepasados como fuente de poder espiritual para ser empleada por los vivos, se encuentra ausente en la sociedad mapuche". Estas proposiciones, que contrarían buena parte de la investigación etnohistórica y etnográfica referenciada en nuestro artículo, se pueden explicar en parte como reflejo de los procesos de transformación de las representaciones religiosas a los que previamente hemos aludido. Ellas pueden ser válidas consideradas etnográficamente, como la caracterización de situaciones locales, pero carecen de validez general. 
para que todos los participantes le hagan oraciones y ofrendas a sus propios antepasados. En el área williche hemos registrado multimedialmente una variante del mismo en el culto a espíritus ancestrales locales emplazados en el espacio (Moulian, 2008).

Si bien la conservación de cráneos de parientes y afines es un patrón poco documentado, los antecedentes expuestos al respecto son consistentes, muestran recurrencia y congruencia con las pautas de ancestralización mapuche. Esta práctica vinculante con los ancestros es compartida por los chipaya (Wachtel, 2001) quienes conservan comunitariamente los cráneos de los antepasados fundadores. La misma costumbre también se registra entre los kallawaya, aunque de modo individualizado (Fernández, 2011), quienes emplean los cráneos en rituales de adivinación o como celadores de sus casas. Allen (2008) igualmente la documenta entre la población quechua de Sonqo, donde se emplean las calaveras de los difuntos de la familia para proteger los depósitos de alimentos. Carmichael (1994) ha propuesto una lectura del uso de las cabezas entre los nasca como un patrón de ancestralización. Este uso se mantiene vigente en algunas familias tradicionales de Cusco que preservan las cabezas de sus abuelos o padres, cuyas almas cuidan las pertenencias y personas de sus casas.

Se trata de una costumbre ampliamente difundida $\mathrm{y}$ vigente hasta la actualidad en el mundo andino, donde se ocupan las cabezas humanas de familiares o desconocidos con esta función. Hemos recogido antecedentes de esta práctica en el valle de Supe, al norte de Lima, donde se disponían las calaveras para cuidar las huertas. En caleta de Carquín, colindante con la ciudad de Huacho, los pobladores del sector Virgen del Carmen sitúan sobre el techo y puertas de sus viviendas los cráneos que han encontrado al construir sus moradas. De acuerdo a la creencia popular, las almas de las personas a las que corresponden estas osamentas actúan de celadoras.

La "Fiesta de las Natitas", realizada en torno a la capilla del cementerio central de La Paz, cada 8 de noviembre, muestra la importancia y popularidad del culto a los cráneos humanos entre la población de raíz aymara. Allí se congregan los depositarios de más de mil calaveras, quienes llevan las cabezas en cajas, urnas y vitrinas portátiles, para recibir la bendición sacerdotal, engalanadas con flores y guirnaldas, revestidas de sombreros, lentes, bufandas, con las cuencas de sus ojos rellenas de algodón (Figura 6). Tras la ceremonia, la acción continúa en el patio del campo santo, donde se sirven ofrendas de alimentos y bebidas a las cabezas, les prenden velas, también cigarrillos con los que las hacen fumar y les ofrecen piezas de música, ejecutadas por grupos instrumentales que venden sus servicios para la ocasión. Los cráneos son contenedores de las almas, que sirven de protectoras e intercesoras en favor de los intereses de sus dueños. Cuando la situación lo permite y amerita, la celebración se prolonga en una fiesta en la que los depositarios de las cabezas invitan a amigos, familiares, trabajadores y vecinos con alimentos, bebida y bailes, para pagar los favores concedidos por las "ñatitas".

\section{Antecedentes amerindios}

El simbolismo de la cabeza tiene profundidad histórica, persistencia y una extraordinaria difusión en el mundo andino y amazónico. Si bien este motivo presenta una difusión universal, en tanto se registra en culturas de los cinco continentes (Chacon y Dye, 2007), los datos arqueológicos, etnohistóricos y etnográficos permiten afirmar la existencia de una tradición cultural amerindia en torno a ella, con un notorio arraigo en el horizonte andino (Tello, 1918; Vignati, 1930; Arnold y Hastorf, 2008; Tonda, 2015). Tello (1918) advierte la recurrencia y complejidad de este motivo que se encuentra en culturas amazónicas como la jíbara, munduruku; del chaco como la guaraní y guaikuru; andinas como la chavín, cupisnique, paracas, moche, nasca, wari, tiwanaku, inca y colla; y patagónica como la mapuche. El padre de la arqueología peruana asocia su presencia a las variantes contextuales de la retórica guerrera y el culto a los ancestros. Por su función política y comunicativa, de contenidos disuasorios y carácter público, la primera variante se encuentra ampliamente representada en múltiples soportes. La segunda, en cambio, se desarrolla en la intimidad y se expresa con menor frecuencia en los sistemas figurativos.

Las evidencias osteológicas más antiguas de decapitación en América han sido reportadas en Lagoa 


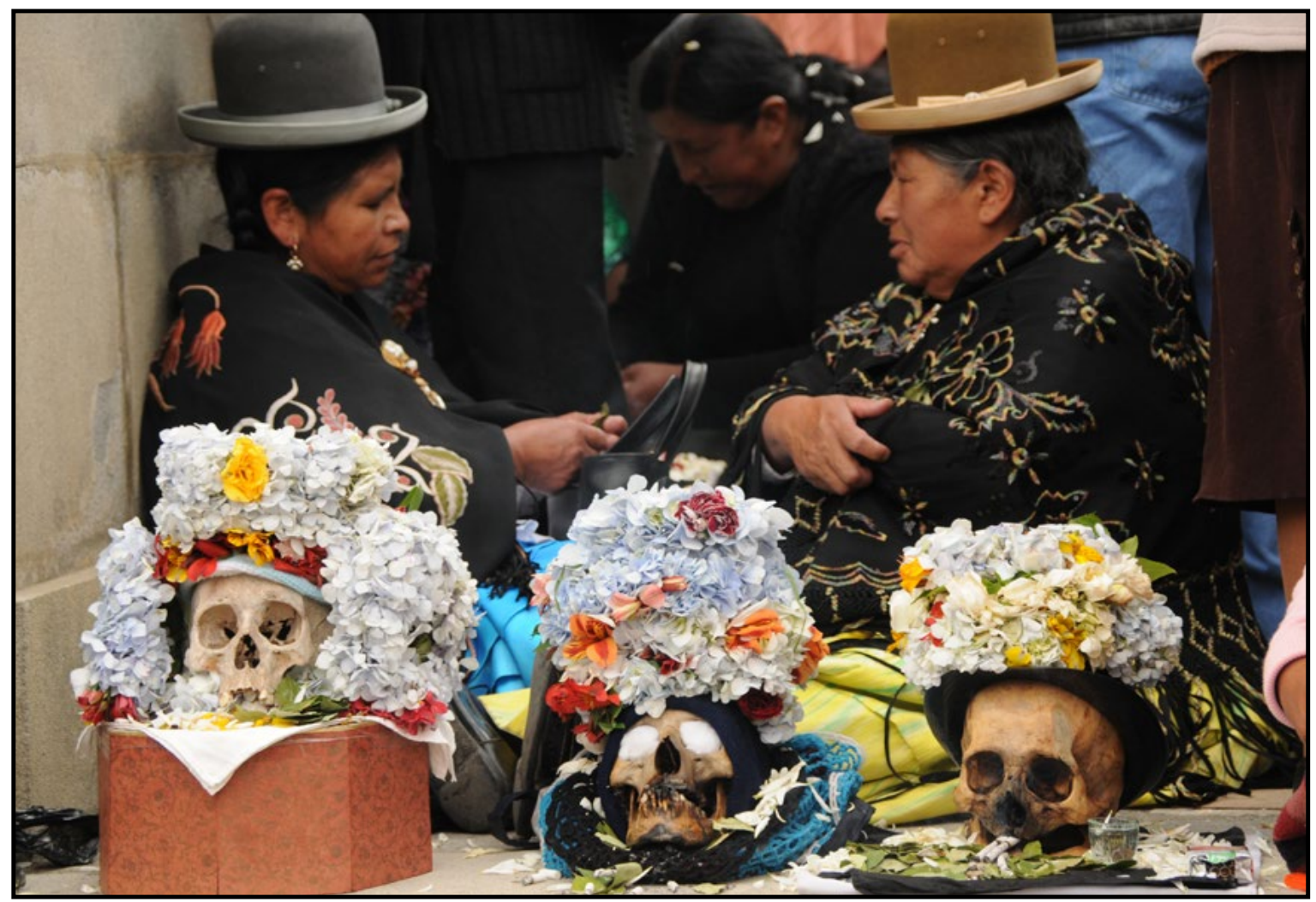

Figura 6. Uso ritual de los cráneos en la fiesta de 'las ñatitas’ en La Paz. Fotografía de Rodrigo Moulian.

Santa, en el centro de Brasil, con una antigüedad de 7 mil ańos AC. (Strauss et al., 2015). En el área andina, el registro más temprano de desmembramiento corporal y uso de la cabeza como ofrenda se encuentra en el sitio Asia del valle de Omas, en la costa central del Perú, datada entre 1300 y 1100 AC (Tung, 2007). No obstante, el motivo de la cabeza ya se encuentra en el repertorio iconográfico de Caral, la ciudad más antigua del continente, situada en la zona costera central de Perú, con una data de 3 mil ańos AC. Allí se emplea bajo el formato de geoglifo, diseńado para ser avistado desde las montañas del entorno, a modo de señal. También se sitúa en los murales líticos del complejo arqueológico.

En términos estéticos, el diseño de las cabezas en Caral se vincula a las figuras corporales de la llamada "fortaleza de Sechín", en Casma, datada 1800 años AC, cuyos muros exponen las primeras escenas de desmembramiento humano. El edificio de planta cuadrada ostenta en su fachada externa un mural compuesto por 304 tallas. Las columnas del recinto representan soldados marchando con su indumentaria bélica; las paredes exponen cabezas decapitadas, miembros mutilados, cuerpos seccionados, vísceras expulsadas del tronco (Samaniego, 1980). El sitio es considerado uno de los primeros exponentes del simbolismo sacrificial que es una constante en la imaginería andina.

Uno de los elementos más distintivos de esta tradición es la figura del decapitador, personaje que porta un báculo o cuchillo y cabezas trofeo. Esta figura, asociada a las prácticas sacrificiales, es una constante en la imaginería andina y se encuentra profusamente representada en los textiles de la cultura paracas, en la iconografía mochica, en los repertorios simbólicos nasca, wari, tiwanaku, constituyendo "un elemento co-tradicional andino" (Núneez, 1964). Variantes del motivo del sacrificador se encuentran en el arte rupestre y tabletas inhalatorias del área 
de San Pedro de Atacama (Mostny, 1954; Torres, 1984; Llagostera, 2004; López, 2007). En tanto, el carácter público de los rituales sacrificiales y su asociación a complejos arquitectónicos monumentales se encuentran especialmente bien expuestos en la cultura mochica (Mosner, 1974; Cordy-Collins, 2001; Bock, 2012).

No obstante, la decapitación no se restringe al simbolismo guerrero. Un estudio de los patrones figurativos de cerca de 300 piezas textiles sobre el motivo de la cabeza en la cultura paracas (Paul, 2000) identifica dos variantes representativas: la cabeza trofeo y la cabeza vitalizada. Las primeras se llevan colgadas desde una soga, con las calotas hacia abajo y el cabello suspendido. Las segundas muestran signos vitales; en ocasiones llevan la boca abierta desde donde brotan sus lenguas mientras sus cabelleras desafían la ley de gravedad. De acuerdo a la autora, las primeras se pueden asociar a las prácticas sacrificiales, pero las segundas parecen vinculadas al culto a los ancestros y propiciación de la fertilidad. Así lo había advertido previamente Valcárcel (1978, p. 78) quien plantea que la representación de la cabeza no es siempre ni necesariamente un símbolo bélico, pues aparece relacionado con la magia destinada a las prácticas agrícolas: "la cabeza humana tiene que ver con la producción de la tierra, está relacionada con los frutos, ella misma es como un fruto. La lúcuma es RukuUma en quechua 'cabeza de viejo'. La tutuma es otro nombre de la cabeza humana y lo es de un fruto. La cabeza tiene que ver con la calabaza y con la maraca. Parece que también tiene algo que hacer con la luna”.

La coexistencia de estas polaridades simbólicas, en el sentido de Turner (1999), se advierte, por ejemplo, en la cultura nasca, heredera de la tradición paracas. El registro arqueológico ha permitido documentar en ella el uso de las cabezas trofeos especialmente intervenidas para su uso simbólico y más tarde depositadas como ofrendas fúnebres. Los nascas retiran la masa encefálica del cráneo, pero conservan la piel del rostro, el cabello y atan la mandíbula a los arcos cigosomáticos para que ésta mantenga su posición anatómica original. De modo análogo a los jíbaros, en ocasiones cosen la boca y los párpados con espinas de algarrobo. También rellenan las mejillas con algodón, vegetales o cabello de la víctima. En tanto, el hueso frontal es perforado para pasar a través de él una soga que permite hacer de la cabeza una cuelga (Verano, 2003; Bovisio y Costas, 2012). La iconografía sobre piezas cerámicas nasca muestra escenas de guerra en las que los combatientes decapitan a sus adversarios (Proulx, 2001).

No obstante, la cultura nasca también produce vasos y contenedores de cerámica diseñados o pintados en forma de cabezas desde las que brotan especies vegetales, lo que plantea la interpretación metafórica del simbolismo de la cabeza como semilla desde la cual renace la vida (Conlee, 2007) y se asocia al poder generativo de los antepasados. Aunque con reservas respecto de la ancestralidad, esta idea ha sido planteada previamente por Proulx quien destaca la asociación entre las nociones de muerte / decapitación / sangre y regeneración / renacimiento / fertilidad agrícola. En palabras del autor (1999, p. 9): "Creo que el uso primario de las cabezas trofeo en la sociedad nasca fue de naturaleza mágica para asegurar la continuidad de la abundancia de los cultivos alimentarios. La gente nasca debe haber dado mucha importancia en su visión de mundo a las cabezas humanas como fuente de poder". A la cabeza se le atribuye una fuerza generativa.

Como advierte Eliade (1974), el símbolo no solo es un mecanismo de integración de significados, sino de tránsito que permite desplazarnos por las distintas zonas de sentido que se le atribuye. $\mathrm{Al}$ respecto, Arnold y Espejo (2007) muestran que estas nociones previamente reseñadas permanecen vivas en el pensamiento aymara contemporáneo. La emergencia de conflictos territoriales entre ayllus ha reactivado la caza de cabezas, que no solo opera como símbolo de capacidad militar, sino como instrumento ritual al servicio de la reproducción social.

Esta bifurcación del simbolismo de la cabeza entre componentes bélicos y reproductivos se manifiesta, igualmente, en la cultura inca. Guaman Poma de Ayala ilustra en su Coronica (1980) las prácticas de decapitación asociadas al militarismo incaico. Los "aucacamayoc", soldados imperiales, se muestran exhibiendo las cabezas arrebatadas a sus enemigos (ver Figura 1). El cronista también registra el desplazamiento de estos elementos corporales hacia la fuente del poder político, encarnada en el "sapa 
inca" o emperador, quien recibe las testas de los líderes derrotados como prueba de los éxitos de sus capitanes (ver Figura 2). Conservadas como trofeos, en ocasiones éstas eran repujadas en oro y plata y empleadas como vasos ceremoniales. Esta tendencia a la cosificación de las cabezas contrasta con la concepción vivificada de las mismas que se advierte en el "mito del inkarri". Este relato refiere a la decapitación del "rey Inca”, en cuya cabeza separada del cuerpo y conservada por los españoles continúa latente su energía vital. De acuerdo a las versiones del mito, desde ella se está regenerando el cuerpo. El día en que éste se reconstituya o bien se reúna con aquél se restablecerá el antiguo orden.

Diversas versiones de este mito circulan hasta el presente por la Araucanía y Futawillimapu (Contreras, 1991; Gissi, 1997; Ajens, 2016), releídas en clave local. En ellas, Atahualpa es considerado un "rey mapuche", que muere decapitado por los españoles, pero cuya cabeza permanece viva. En una versión registrada por nosotros en la comunidad de Maihue Carimallín, cuando la cabeza se encuentre con el cuerpo, los mapuche recuperarán su poder. Un simbolismo análogo se encuentra en algunas versiones del relato de "El Viejo Latrapai" (Kuramochi, 1984), donde desde la sangre que brota de la cabeza decapitada del anciano renacen sus hijas. A la inversa, en el epew "La mujer del muerto" (Saunière, 1975), la decapitación es el modo de librarse de un alwe que acosa a su viuda y se alimenta de su sangre. La idea de la cabeza vitalizada y fértil presente en estas narrativas resulta convergente y concordante con las representaciones de los relatos sobre el tripanlongko y las prácticas del katulongkon caracterizadas en este artículo.

\section{A modo de conclusión}

Las variantes en el uso simbólico de las cabezas humanas entre los reche-mapuche adscriben a la tradición de las "cabezas trofeo" y procesos de ancestralización comunes a la macrorregión andinaamazónica. La práctica del katulongkon o decapitación, manifiesta en la costumbre de tomar del campo de batalla las cabezas de los enemigos muertos en combate y el sacrificio ritual de los prisioneros; el ñamkuln o exhibición de las cabezas en las picas; el ralilongko o uso de los cráneos como vasos rituales y el purulongkon o baile de las cabezas, forman parte de este simbolismo de prestigio guerrero. Éste distingue a los hombres fuertes, sirve de enseña de poder y activa una memoria épica, de hechos memorables dignos de recordar, que se expresan en discursos y narrativas transmitidos de generación en generación. La circulación e intercambio de cabezas opera como un mecanismo de alianza, movilización social y acumulación político-militar de fuerzas. En tanto, la conservación y uso ritual de la cabeza de correligionarios y la referencia al entierro de cráneos de parientes bajo las ruka informan la ancestralización de este órgano corporal, empleado para vincularse con los antepasados.

La decapitación y acceso a las cabezas trofeo y la ancestralización y manejo de los cráneos de miembros del propio grupo social operan bajo la común representación de la cabeza como un contenedor espiritual. En el mundo andino-amazónico su administración permite acceder y controlar la energía vital de sus ascendientes. Los usos rituales de las mismas entre los reche como mecanismo oracular que augura el porvenir en las empresas militares, como instrumento propiciatorio que muestra sus atributos mágico-religiosos o instrumento de dominio espiritual confirman esta idea. Sus prácticas implican la noción de que los cráneos mantienen parte de los atributos de los sujetos de origen. Las representaciones de este órgano en las narrativas tradicionales le atribuyen una fuerza vitalizadora y capacidad reproductiva. Las prácticas chamánicas muestran el carácter liminar de la cabeza como puerta de entrada y salida del espíritu. Ella se representa como el depósito de una fuerza animante que sustenta la vida, la que, si bien se expresa en el conjunto del cuerpo, se concentra en su segmento superior. Esta concepción se encuentra implicada, igualmente, en la acepción política del término 'longko' que emplea la metáfora corporal para la caracterización del grupo social y asigna a quienes detentan esta denominación la autoridad comunitaria y capacidad de dirección, como depositarios de un kupalme püllu o linaje espiritual.

Las prácticas y representaciones previamente reseñadas, que caracterizan el simbolismo de la cabeza entre los reche-mapuche, constituyen motivos recurrentes en el mundo andino amazónico. Si bien 
patrones similares han sido documentados en otras áreas, la profundidad histórica, el grado de difusión geográfica y cultural y su persistencia, permiten postular la existencia de una cotradición en torno al simbolismo de la cabeza en esta macro-región. Los datos expuestos muestran paralelismos en las concepciones pneumatológicas, anatómicas y cúlticas que se expresan en configuraciones rituales análogas, calcos semánticos y narrativas comunes. La extensión de estas correlaciones es un indicador de la existencia de relaciones de contacto e interacción cultural de larga data en el mundo andinoamazónico. Ello permite explicar la existencia de patrones transculturales en torno al motivo simbólico de la cabeza que se manifiesta en el contexto reche-mapuche, con una fenomenología particular, de la que ésta es una expresión.

\section{Agradecimientos}

Al Fondo de Desarrollo Científico y Tecnológico de Chile que ha hecho posible la investigación donde se produce este trabajo, a través de los proyectos FONDECYT 1160388, “Translingüística, supralingüística e interculturalidad: un estudio de casos de correlaciones en constelaciones semióticas centro y sur andinas indicadoras de cotradición" y FONDECYT 1120139, "La impronta andina en el sistema religioso cosmovisionario mapuche williche: relaciones significantes, transformaciones simbólicas y encrucijadas de sentido en el espacio centro y sur andino". A Pablo Espinoza y Pedro Galindo por su colaboración en la edición del texto. A Lucy Jemio por permitirnos consultar el Archivo de Literatura Oral de la Carrera de Literatura de la Universidad Nacional de San Andrés, La Paz, Bolivia. A los evaluadores anónimos, cuyas observaciones han contribuido a fortalecer este texto.

\section{Referencias citadas}

Abercrombie, T. (2006). Caminos de la memoria y del poder. Etnografia e historia en una comunidad andina. La Paz: Sierpe.

Acevedo, I. (1989). Sacrificios humanos y canibalismo ritual entre los araucanos (siglo XVI). Tesis para optar al grado de Licenciado en Historia. Santiago: Universidad de Chile.
Acevedo, I. (1995). Cráneos humanos como objeto de culto. Una visión del mundo andino y mapuche a través de las crónicas. Siglos XVI. XI Jornadas de Historia de Chile, Osorno.

Ajens, A. (2016). La conexión huilliche altoperuana. Manuscrito inédito facilitado por el autor.

Allen, C. (2008). La coca sabe. Coca e identidad cultural en una comunidad andina. Cusco: Centro Bartolomé de Las Casas.

Ansión, J. (1987). Desde el rincón de los muertos: el pensamiento mítico en Ayacucho. Lima: Gredes.

Arnold, D. y Espejo, E. (2007). Cabezas de la periferia, del centro y del mundo interior. En Arnold, D., Yapita, J. D. y Espejo, E. (Eds.). Hilos sueltos: Los Andes desde el textil (pp. 133-177). La Paz: Ilca \& Plural.

Arnold, D. y Hastorf, C. (2008). Heads of state: Icons, power, and politics in the ancient and modern Andes. Walnut Creek: Left Coast Press.

Augusta, F. (1916). Diccionario español-araucano y araucano-español: Tomo primero. Araucano-español. Santiago: Imprenta Universitaria.

Bacigalupo, A. (1995). El rol sacerdotal de la machi en los valles centrales de la Araucanía. En Parker, C. (Dir.). ¿Modernización o sabiduría en tierra mapuche? (pp. 6195). Santiago: San Pablo.

Bacigalupo, A. (2007). Shamans of the foye tree: Gender power, and healing among Chilean Mapuche. Austin: University of Texas Press.

Bacigalupo, A. (2010). Relaciones de género ritual: parentesco, matrimonio, dominio y modalidades de persona para los chamanes mapuche. Revista Austral de Ciencias Sociales 18, 83-106.

Bacigalupo, A. (2016). Thunder shaman: Making history with Mapuche spirits in Chile and Patagonia. Austin: University of Texas Press.

Bibar, G. de (1966). Crónica y relación copiosa y verdadera de los reynos de Chile. Edición facsimilar. Santiago: Fondo Histórico y Bibliográfico José Toribio Medina. 
Boccara, G. (2009). Los vencedores. Historia del pueblo mapuche en la época colonial. Santiago: UCN-IIAM / Ocho Libros Editores.

Bock, E. (2012). Sacrificios humanos para el orden cósmico y la regeneración. Estructura y significado en la iconografía moche. Lima: Ediciones SIAN.

Bovisio, M. y Costas, M. (2012). Cabezas trofeo: cuerpo objeto y representación. Primer Encuentro Latinoamericano de Investigadores sobre Cuerpos y Corporalidades en las Culturas, Facultad de Humanidades y Artes, Universidad Nacional de Rosario, CD ROM.

Carmichael, P. (1994). The life from death continuum in Nasca imagery. Andean Past, 4, 81-90.

Carrasco, H., Contreras, V. y García, M. (1998). Elementos constitutivos de la matriz simbólica de tres relatos míticos mapuche. Estudios Filológicos, 33, 145-154.

Comisión de Trabajo Autónomo Mapuche. (2003). Informe de la Comisión de Verdad Histórica y Nuevo Trato. Volumen 3 anexo a Tomo II. Informes Finales de Grupos de Trabajo. Recuperado de Recuperado de http://www. serindigena.org/libros_digitales/cvhynt/v_iii/t_i/informe_final_grupo_juridico_(1).pdf

Conlee, C. (2007). Decapitation and rebirth: A headless burial from Nasca, Peru. Current Anthropology, 48(3), 438-445.

Contreras, C. (1991). El mito del rey inca entre los huilliches. Nutram, 7(1), 14-32.

Cordy-Collins, A. (2001). Decapitation in Cupisnique and early Moche societies. En Benson, E. y Cook, A. (Eds.). Ritual sacrifice in ancient Peru (pp. 21-33). Austin: University of Texas Press.

Course, M. (2008). Mapuche ñi Mongen: Individuo y Sociedad en la Vida Mapuche Rural (M. González trad.). Temuco: Instituto de Estudios Indígenas Universidad de La Frontera.

Course, M. (2011). Becoming Mapuche: person and ritual in indigenous Chile. Champaign: University of Illinois Press.

Chacon, R. y Dye, D. (2007). Introduction to human trophy taking: An ancient and widespread practice. En
Chacon, R. y Dye, D. (Eds.). The taking and displaying of human body parts as trophies by Amerindians (pp. 5-31). Nueva York: Springer.

Descola, P. (2002). La antropología y la cuestión de la naturaleza. En Palacios, G. y Ulloa, A. (Eds.). Repensando la Naturaleza: encuentro y desencuentro ambientales en torno a lo ambiental. Leticia: Universidad Nacional de Colombia.

Descola, P. (2005). Las lanzas del crepúsculo: relatos jibaro, alta amazonía. Buenos Aires: Fondo de Cultura Económica.

Di Giminiani, P. (2012). Tierras ancestrales, disputas contemporáneas: pertenencia y demandas territoriales en la sociedad mapuche ancestral. Santiago: Ediciones Universidad Católica.

Dillehay, T. (1990). Araucania: presente y pasado. Santiago: Andrés Bello.

Domeyko, I. (2010). Araucania y sus habitantes. Santiago: Cámara Chilena de la Construcción/ Pontificia Universidad Católica/ Biblioteca Nacional.

Eliade, M. (1974). Tratado de historia de las religiones. Tomo II. Madrid: Ediciones Cristiandad.

Erize, E. (1960). Diccionario comentado mapuche español. Buenos Aires: Universidad Nacional del Sur.

Faron, L. (1997). Antupaiñamko: moral y ritual mapuche. Santiago: Ediciones Mundo.

Fausto, C. (2001). Inimigos fiéis: história, guerra e xamanismo na Amazônia. San Pablo: Editora da Universidade da São Paulo.

Febres, A. (1765). Arte de la lengua general del reyno de Chile. Lima: Calle de la Encarnación. Recuperado de http:// www.memoriachilena.cl/602/w3-article-8486.html

Fernández, G. (2011). Natitas, 'almas' y 'condenados'. Trasiego de osamentas en los Andes, siglo XVI-XXI. En Izquierdo, R. y Martínez, F. (Coords.). Religión y heterodoxias en el mundo hispánico: Siglos XIV-XVIII (pp. 229253). Madrid: Sílex Ediciones.

Flornoy, B. (1953). Jivaro: Among the headshrinkers of the Amazon. Londres: Elek. 
Foerster, R. (1995). Introducción a la religiosidad mapuche. Santiago: Universitaria.

García Escudero, M. (2010). Cosmovisión inca: Nuevos enfoques y viejos problemas. Tesis doctoral. Madrid: Universidad Complutense de Madrid.

Gissi, N. (1997). Aproximación al conocimiento de la memoria mapuche-huilliche de San Juan de La Costa. Tesis para optar al título de Antropólogo Social. Santiago: Universidad de Chile.

González de Holguín, D. (2007). Vocabvlario de la lengva general de todo el Perv, llamada lengua qquichua, o lengva del Inca. Recuperado de http://www.illa-a.org/cd/diccionarios/VocabvlarioQqichuaDeHolguin.pdf

Goicovich, F. (2003). En torno a la asimetría de los géneros en la sociedad mapuche del período de la conquista hispana. Historia, 36, 159-178.

Goicovich, F. (2006). Alianzas geotectónicas en la segunda rebelión general: génesis y dinámicas de los vutanmapus en el alzamiento de 1598. Historia, 39, 93-154.

González, M. (2007). Cuando se necesitan representantes pero no se admite la representación. Notas para la comprensión del liderazgo en las comunidades mapuche. Actas del VI Congreso Chileno de Antropología. Tomo I, 1006-1013.

González, M. (2016). Los mapuche y sus otros: persona, alteridad y sociedad en el sur de Chile. Santiago: Universitaria.

González de Nájera, A. (1889). Desengaño y reparo de la guerra del reino de Chile. Santiago: Imprenta Ercilla.

Grebe, M; Pacheco, S. y Segura, J. (1972). Cosmovisión mapuche. Cuadernos de la Realidad Nacional, 14, 46-73.

Guaman Poma de Ayala, F. (1980). Nueva Coronica y Buen Gobierno. Caracas: Biblioteca Ayacucho.

Guevara, T. (1908). Psicolojía del pueblo araucano. Santiago: Imprenta Cervantes.

Guevara, T. (1929a). Historia de Chile Prehispano. Tomo I. Santiago: Establecimientos Gráficos Balcells.

Guevara, T. (1929b). Historia de Chile Prehispano. Tomo II. Santiago: Establecimientos Gráficos Balcells.
Harner, M. (1978). Shuar: pueblo de las cascadas sagradas. Quito: Ediciones Mundo Shuar.

Havestadt, B. (1883). Chiledúǵu sive tractatus linguae chilensis. Vol. II. Platzmann, J. (Ed.). Reimpresión sin adiciones. Leipzig: B. G. Teubner. Recuperado en http://www. memoriachilena.cl/602/w3-article-8488.html

Hernández, A. y Ramos, N. (2002). Mapuche: lengua y cultura. Santiago: Pehuén.

Karsten, R. (2000). La vida y la cultura de los shuar. Quito: Abya-Yala.

Koessler-Ilg, B. (2006). Cuenta el pueblo mapuche. Vol. 1. Tradiciones. Santiago: Editorial Mare Nostrum.

Kuramochi, Y. (1984). Los donantes en 'el viejo Latrapai'. Actas de Primeras Jornadas de Lengua y Literatura Mapuche (pp. 89-102).

Kuramochi, Y. y Huisca, R. (1997). Cultura mapuche. Relatos, rituales y ceremonias. Quito: Abya-Yala.

Ladino, M. (2014). Espiritualidad mapuche. Santiago: Ediciones Jurídicas.

Latcham, R. (1924). La organización social y las creencias religiosas de los antiguos araucanos. Santiago: Imprenta Cervantes.

López, C. (2011). El palin: juego tradicional de la cultura mapuche. Valparaíso: Ediciones Universitarias de Valparaíso.

López, M. (2007). Interpretación simbólica de la iconografía del sacrificador el señor de los cetros. Una visión desde los mitos. Memoria para optar al título de Arqueólogo. Santiago: Universidad de Chile.

Lotman, I. y Escuela de Tartu (1978). Semiótica de la cultura. Madrid: Cátedra.

Llagostera, A. (2004). Los antiguos habitantes del salar de Atacama: Prehistoria atacameña. Santiago: Pehuén Editores.

Mader, E. (1999). Metamorfosis del poder: persona, mito y poder en las sociedades Shuar y Achuar (Ecuador y Perú). Quito: Ediciones Abya-Yala. 
Margery, E. (2003). Estudios de mitología comparada indoamericana. San José: Editorial Universitaria de Costa Rica.

Menget, P. (1996). De l'usage des trophées en Amérique du Sud. Esquisse d'une comparaison entre les pratiques nivacle (Paraguay) et mundurucu (Brésil). Systèmes de pensée en Afrique noire, 14, 127-143.

Millones, L. (2010). Después de la muerte. Voces del infierno y el limbo en territorio andino. Lima: Fondo Editorial del Congreso de Perú.

Monart, G. (2005). Manual y glosario de la cultura y la lengua mapuche pampa o mapudungun rankülche. Buenos Aires: Agencia Periodística CID.

Montecino, S., Artigas. D., Phillipi, L. y Obach, A. (2003). Mitos de Chile. Diccionario de seres, magias y encantos. Santiago: Sudamericana.

Morote, E. (1953). Cabezas voladoras. Perú Indígena, 4(9), $109-124$.

Moser, Ch. (1974). Ritual decapitation in Moche art. Archaeology, 27(1), 30-37.

Mostny, G. (1958). Máscaras, tubos y tabletas para rapé y cabezas trofeo entre los atacameños. En Miscellanea Paul Rivet, Octogenario Dicata, Vol II (pp. 379-392). México: Universidad Nacional Autónoma de México.

Moulian, R. (2008). Ngen rüpu/ El camino del ngen. Un trabajo de etnografía multimedia y arqueología de los simbolos. Valdivia: Universidad Austral de Chile / Consejo Nacional de la Cultura y de las Artes.

Moulian, R. y Espinoza, P. (2014). Pneumatología, paisaje y culto: patrones andinos en los procesos de ancestralización de la cultura mapuche emplazados en la naturaleza. Chungara. Revista de Antropología Chilena, 46(4), 637650 .

Nielsen, A. (2007). Armas significantes: Tramas culturales, guerra y cambio social en el sur andino prehispánico. Boletín del Museo Chileno de Arte Precolombino, 12(1), 9-41.

Núñez de Pineda, F. (1863). Cautiverio feliz y razón individual de las guerras dilatadas. Santiago: Imprenta del Ferrocarril.
Núñez, L. (1964). El sacrificador. Un elemento co-tradicional andino. Noticiario Mensual. Museo Nacional de Historia Natural, 8(98), sp.

Oyarce, A. y González, E. (1986). Kallfulikan, un canto mapuche: descripción, análisis musical y sus correspondencias con el aspecto literario. Actas de Jornadas de Lengua y Literatura Mapuche, 2, 245-263.

Paredes, A. (1972). Diccionario mitológico de Bolivia. La Paz: Ediciones Puerta del Sol.

Paul, A. (2000). Bodiless human heads in Paracas: Necropolis textile iconography. Andean Past, 6, 69-94.

Plath, O. (1976). El lenguaje de los pájaros chilenos: Avifauna folklórica. Santiago: Nascimento.

Proulx, D. (1971). Headhunting in ancient Peru. Archeology, 24(1), 16-21.

Proulx, D. (1999). Nasca headhunting and the ritual use of trophy heads. Recuperado de http://people.umass. edu/_proulx/online_pubs/Nasca_Headhunting_Zurich. pdf

Proulx, D. (2001). Ritual uses of trophy heads in ancient Nasca society. En Benson, E. y Cook, A. (Eds.). Ritual sacrifice in ancient Peru (pp. 119-136). Austin: University of Texas Press.

Quilaleo, D. (2012). Saberes educativos mapuche: racionalidad apoyada en la memoria social de los kimches. Atenea, 505, 70-102.

Ríos, S. (2008). Un acercamiento al mundo del human tac tac en los Andes. Artesanías de América, 66, 103-124.

Rojas, P. (2016). El rito fúnebre mapuche del descanso: una muda ontológica al árbol de los ancestros. Chungara. Revista de Antropología Chilena, 48(4), 657-678.

Rojas, P. (2016) Los descansos en el proceso mortuorio mapuche: de la muda ontológica a la morada de los ancestros. Valdivia: Consejo Nacional de la Cultura y las Artes / TextoContexto.

Rosales, D. (1877). Historia general del reyno de Chile, Flandes Indiano. Tomo I. Valparaíso: Imprenta El Mercurio.

Rosales, D. (1878). Historia general del reyno de Chile, Flandes Indiano. Tomo II. Valparaíso: Imprenta El Mercurio. 
Rosales, D. (1991). Seis misioneros en la Araucanía. Temuco: Ediciones Universidad de La Frontera.

Salas, A. (1992). El mapuche o araucano. Fonología, gramática y antología de cuentos. Madrid: Mapfre.

Saignés, T. y Salazar-Soler, C. (1993). Borrachera y memoria: La experiencia de lo sagrado en los Andes. La Paz: Hispol.

Samaniego, L. (1980). Informe sobre los hallazgos de Sechín. Indiana, 6, 307-348.

Santos, S., Salles, A., Mendonça de Souza, S. y Nascimento, F. (2007). Os Munduruku e as cabeças-troféu. Revista do Museu de Arqueologia e Etnologia, 17, 365-380.

Saunière, R. (1975). Cuentos populares araucanos y chilenos. Santiago: Nascimento.

Savio, J. (2007). A guerra implacável dos Munduruku: elementos culturais e genéticos na caça aos inimigos. Avá, Revista de Antropología, 11, 169-189.

Silverman, H. (1993). Cahuachi in the ancient Nasca world. Iowa City: University of Iowa Press.

Strauss, A., Oliveira, R., Bernardo, D.V., Salazar-García, D., Talamo, S., Jaouen K. et al. (2015). The oldest case of decapitation in the New World (Lapa do Santo, East-Central Brazil). PLoS ONE, 10 (9). Recuperado de http://journals.plos.org/plosone/article?id=10.1371/journal.pone.0137456.

Tello, J. (1918). El uso de las cabezas humanas artificialmente momificadas y su representación en el antiguo arte peruano. Revista Universitaria, 13(2), 477-533.

Tonda, D. (2015). Cabeza trofeo en el mundo andino preincaico. Tradición y cambio. Tesis de grado en Historia. Barcelona: Universidad de Barcelona.

Torres, C. (1984). Tabletas para alucinógenos en San Pedro de Atacama: Estilo e iconografía. En Tesoros de San Pedro de Atacama (pp. 23-36). Santiago: Museo de Arte Precolombino.

Tung, T. (2007). From corporeality to sanctity: Transforming bodies into trophy heads in the Pre-Hispanic Andes. En Chacon, R. y Dye, D. (Eds.). The taking and displaying of human body parts as trophies by Amerindians (pp. 481-504). Nueva York: Springer.
Turner, V. (1999). La selva de los simbolos. Madrid: Siglo XXI.

Uribe, C., Varela, V., Cervantes, S., González, C. y Rodríguez, M. (2013). Tradiciones atacameñas. Consejo Nacional de la Cultura y las Artes. Recuperado de http://pci. tradicionesdeatacama.cl

Valcárcel, L. (1978). Historia del antiguo Perú a través de la fuente escrita. Tomo I. Lima: Editorial Juan Mejía Baca.

Valdivia, L. (1887). Arte y gramática general de la lengva que corre en todo el reyno de Chile con vn confessionario y vocabvlario. Platzmann, J. (Ed.). Leipzig: B. G. Teubner. Recuperada de http://www.memoriachilena.cl/602/w3article-8485.html

Valdivia, L. (1852). Relación de lo sucedido en la jornada que hicimos el señor preste Alonso de Ribera gobernador del reyno y yo desde Arauco á Paycavi á a conducir las paces de Iliucura ultima regua de Tucapel y las de Puren y la Imperial. En Gay, C. (Comp.). Historia física, politica de Chile. Tomo II (pp. 281-294). Santiago: Museo Nacional de Historia Natural.

Verano, J. (1995). Where do they rest? The treatment of human offerings and trophies in ancient Peru. En Dillehay, T. (Ed.). Tombs for the living: Andean mortuary practices (pp. 189-227). Washington: Dumbarton Oaks.

Verano, J. (2003). Mummified trophy heads from Peru: Diagnostic features and medicolegal significance. Journal of Forensic Sciences, 48 (3), 525-530.

Verano, J. (2008). Trophy head-taking and human sacrifice in Andean South America. En Silverman, H. e Isbell, W. H. (Eds.). Handbook of South American Archaeology (pp. 1047-1060). Nueva York: Springer-Verlag.

Vicuña, J. (1915). Mitos y supersticiones recogidos de la tradición oral chilena con referencias comparativas a otros paises latinos. Santiago: Imprenta Universitaria.

Vignati, M. (1930). Los cráneos trofeo de las sepulturas de Humahuaca. Buenos Aires: Imprenta de la Universidad.

Villar, D. y Jiménez, J. (2014). En lo alto de una pica. Manipulación ritual, transaccional y política de las cabezas de los vencidos en las fronteras indígenas de América meridional. (Araucanía y las Pampas siglo XVI y XIX). Indiana, 31, 351-376. 
Katulongkon: contextualización y antecedentes transculturales del simbolismo de la cabeza entre los Reche-Mapuche

Waag, E. (1982). Tres entidades wekufu en la cultura mapuche. Buenos Aires: Eudeba.

Wachtel, N. (2001). El regreso de los antepasados. Los indios urus de Bolivia, del siglo XX al XVI. Ensayo de historia regresiva. México: Fondo de Cultura Económica.

(c) (1) Este es un artículo de acceso abierto bajo licencia Creative Commons Reconocimiento 4.0 Internacional 